\title{
Internal Structure of Clitics and Cliticization
}

\author{
Marios Mavrogiorgos \\ University of Cambridge \\ mmavrog@yahoo.gr
}

\begin{abstract}
The role of the internal structure of clitics in cliticization has been investigated by many researchers up to now. In this study I look into three distinct types of analysis that have been proposed in the literature regarding this role and argue that they do not work for Greek. I further propose that the only role the internal structure of clitics can play in cliticization is via their phi-features, which render them active goals. However, I argue that the internal structure is crucial in another respect, namely in the incorporation of the clitic pronoun into its verbal host. This is because in order to incorporate, the clitic has to contain only a subset of the features contained in the incorporation host. Syntactic cliticization in Greek follows from syntactic agreement between the clitic pronoun and the phase head $\mathrm{v}^{*}$, which leads to movement of the clitic to the left edge of $\mathrm{v}^{*}$ and to clitic incorporation into $\mathrm{v}^{*}$. Incorporation yields proclisis.
\end{abstract}

\section{Keywords}

Agree, clitic, Incorporation, phase, proclisis, syntax

\section{Introduction}

Within the generative literature, the investigation of structural and other properties of personal pronouns has a long tradition. Already before the 1970s (see e.g. Postal 1969), linguists have been investigating such properties as the categorial status of pronouns (e.g. whether they are nouns or determiners), their phrase-structure status (e.g. whether they have simplex or complex internal structure), and their exact feature specifications (both lexical and/or functional). In Greek, as well as in other languages, personal pronouns differ in some important respects, although they also appear to share a number of properties. For example, pronouns may be overt or covert, they may have distinct binding properties, they may occupy distinct positions within the clause, or they may contain/realize distinct sets of features. On the other hand, the majority of pronouns do not involve an overt nominal root, which would explain why they do not denote a lexical concept, although they typically denote an individual and pick up their reference either through syntactic 
binding or via coreference (see Grodzinsky \& Reinhart 1993; see also Abney 1987, and Panagiotidis 2002). Moreover, when they are overt they are typically marked for different types of features, such as phi-features or case, although neither the quality nor the quantity or combination of these features has to be the same both within and across distinct types of pronouns (within a single language or across languages). As far as clitic pronouns are concerned, many researchers have argued that their internal structure, including their featural make-up, interacts with their actual syntax within the clause in that it actually gives rise to cliticization. In this article, I claim that these approaches are both empirically and theoretically inadequate. In particular, I argue that what syntactic cliticization boils down to is syntactic agreement between a phase head and the phi features of a clitic head. As a result, the only features that may play a role in the cliticization of a clitic head are its phi-features. I further argue that the internal structure of a clitic plays a role in the incorporation of the clitic into its verbal host, given that incorporation is contingent upon whether the incorporee has only a subset of the features contained by the incorporation host, but not on the clitic movement per se. As a result of this, a minimal approach to the internal structure of clitics is followed, whereby only the necessary features are advocated, but no covert constituents that drive movement.

\section{Some previous analyses proposed for personal pronouns}

The different major analyses that have been proposed in the literature for personal pronouns and for their various sub-types can be distinguished into two basic types. Type A analyses assign a DP status to pronouns (with distinct structures in many cases both within and across pronominal types), while type $\mathrm{B}$ analyses assign a different categorial status to different pronouns (e.g. DPs, $\varphi$ Ps, etc.). Here, I deal only with type A analyses.

\subsection{Type A: DPs}

The first type of analysis treats different types of pronouns as determiners that project a DP. This type can be further divided into three sub-types: (a) (some or all types of) pronouns are intransitive $\mathrm{D}^{0}$-heads projecting a DP (which is merged in a $\theta$-position); (b) (some or all types of) pronouns are transitive $\mathrm{D}^{0}$-heads, taking at least an NP complement and projecting a DP (which is merged in a $\theta$-position); (c) clitic pronouns are $\mathrm{D}^{0}$-heads merged in designated clitic heads within the clausal functional projection. In this 
respect, they strongly resemble other clausal heads (and agreement heads in particular). ${ }^{1}$ Here I look into only subtype (a) and (b) analyses, since I assume that Greek clitic pronouns are not clausal heads, following in this regard Mavrogiorgos (2009).

\subsubsection{Sub-type (a): Pronouns as intransitive $D^{\circ}$-heads projecting a DP}

In the 1980s, Abney analyzed pronouns as intransitive $\mathrm{D}^{0}$-heads that project a DP; when they co-occur with an overt nominal head, an NP is also projected. The same analysis is given for other (optionally) intransitive determiners. This is illustrated below (specifiers omitted):
(1) (a) $\mathrm{DP}$
(b) $\mathrm{DP}$
we/he/she/those/these

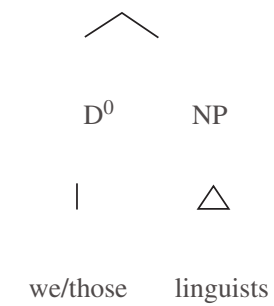

Although Abney does not specifically talk about clitics, neither does he distinguish pronouns into different types, many researchers in the clitic literature in the 1980s and the 1990s simply assumed that clitics are intransitive DPs, on a par with strong pronouns. Some of them, however, tried to link the special distribution of clitic pronouns to the very fact that they were analyzed as intransitive DPs. For instance, Rizzi (1993) argues that Romance clitics are special intransitive determiners (projecting a DP), which are merged in the complement position of the verb, and which contain NP- features that can only be checked DP-externally by the corresponding features on V. This is so, because clitics do not take an (overt) NP complement, which would check its NP- features DP-internally. Furthermore, the reason this checking must be

\footnotetext{
1 Note that clitic heads could also realize such features as Person or Number besides D (see Manzini \& Savoia 2005, 2007 for an analysis of clitics as inflectional/clausal heads and for an extensive discussion of clitics in Italian and other languages. For an analysis of Modern and Medieval Greek clitics see Condoravdi \& Kiparsky 2001, 2004 and for late Medieval Greek see Pappas 2004). As a reviewer points out, assignment of a distinct structural position to clitic heads does not entail an agreement status for them; on the contrary, these positions (e.g. Number, Person, Definiteness, etc.) could help us give content to the 'old' Agr heads.
} 
overt is either linked to the assumption that clitic features are strong ${ }^{2}$ (which, in turn, is linked to the observation that Romance clitics overtly realize case and phi-features (and possibly other features) which are not realized by other determiners within a full noun phrase), or alternatively to the assumption that items with no lexical content are not visible at LF (an observation that is attributed to Chomsky 1993). Accordingly, the exact derivation of a monotransitive accusative clitic structure like la conosco ('her I-know') would involve overt movement of the whole DP to the specifier of AGRoP for case checking (a 'V-related landing site'), followed by movement of the $\mathrm{D} /$ clitic head out of the DP to an immediately higher recursive AGR head, AGRcl. ${ }^{3}$

Rizzi's proposal, however, faces a number of problems:

(a) The proposed phi-/case-feature checking of the intransitive clitic $\mathrm{D}^{0}$ head by an appropriate external V-head ( $\mathrm{AgrO}$ or v) should not be possible according to the definition of Agree and the standard minimalist assumptions on feature interpretability, as presented from Minimalist Inquiries (MI) (Chomsky 2000) onwards, given the uninterpretability of phi-features on both the verb and the clitic $\mathrm{D}^{0}$ head. ${ }^{4}$

(b) If phi-features on the $\mathrm{D}^{0}$ head were uninterpretable, it would be expected that they get deleted and erased after checking (see Chomsky 1995). This would predict, among others, that they are not visible at LF. However, this is empirically incorrect, since in many (although not all) instances phi-features on clitics are semantically interpretable.

(c) Finally, it is not at all clear why clitic movement would have to be overt: it is easily conceivable that checking/feature recoverability takes place either at LF or via long distance Agree (following Minimalist Program (MP) or MI/ Derivation by Phase (DbP), respectively). Rizzi argues that overt movement is forced either by strong case features on the clitic or due to the lack of any lexical content/an NP complement (assuming that it is a prerequisite for covert movement). Nevertheless, both arguments are seriously flawed. On the one hand, the idea that clitics contain strong case features (and hence move overtly to their verbal host/head, given the early minimalist assumption that rich morphology somehow correlates with strong features and therefore with overt movement (see Chomsky 1993, Roberts 1993, Rohrbacher 1994 and Vikner 1995)) is based on the empirical fact that clitic pronouns in Romance

\footnotetext{
2 The idea that clitic movement may be linked to the strong case features of clitics (as opposed to full DPs and other DP pronouns) has also been proposed by Belletti (1999) for Romance.

${ }^{3}$ Cardinaletti (1994) and Laenzlinger (1998) follow a similar line of analysis for Romance.

${ }^{4}$ Note that-as Holmberg (2005) has correctly pointed out-a similar problem arises for subject pro under current minimalist assumptions.
} 
inflect for case as opposed to strong DPs/pronouns, which do not. Although this may be true in most Romance languages (although not all of them, as Romanian, for example, has kept case distinctions across the whole (pro)nominal paradigm but has the opposition clitics vs. strong pronouns), it definitely would not work for Greek, which marks case across the whole nominal paradigm:

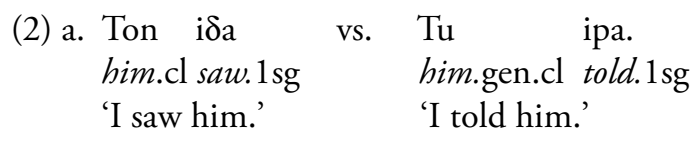
b. I $\delta$ a ekinon/ton Petro.
vs. Ipa ekinu/tu Petru. saw.1sg him.str/the Peter.acc 'I saw him/Peter.' vs. I told him/Peter.' told.1sg him.gen.str/the Peter.gen

In (2) we see that even though (strong) case morphology is marked on clitics, strong pronouns and full DPs, it is only clitics that appear on the left side of the verb. As for the second proposal, namely that clitics have no lexical content and hence would be invisible for LF movement, it hinges on Chomsky's (1993) reasonable speculation that semantically empty constituents are not visible to LF rules such as movement, and therefore they are forced to move overtly. Putting aside the obvious problem of look-ahead that this explanation is facing, the main issue is that (at least some) clitics are not semantically vacuous elements. For instance, they contain interpretable phi-features, such as person (deictic category) and number, semantic features such as specificity or animacy and definiteness, as well as features such as topicality. All these would surely count as semantic content and hence would secure their visibility at LF and as a result their possible LF movement. For this reason, the attribution of cliticization to the lack of NP or of lexical content does not preclude the possibility of clitics moving at LF, and therefore does not explain why clitics must move overtly to their verbal host.

The second important issue that Rizzi's approach has to face and which it shares with transitive $\mathrm{D}$ approaches is the issue of recoverability, namely the idea that clitics are lacking something (syntactic or semantic features) that needs to be recovered via cliticization. The problem with such a view is that it would irrevocably link cliticization with particular syntactic/semantic properties that clitics would have to possess in a uniform way, since cliticization would lead to recovery of the missing features. Unfortunately, this is not what we find empirically. For this reason, I consider the notion of recoverability to be problematic, at least in the way it is used by the intransitive $D$ approaches. 


\subsubsection{Sub-type $\left(b_{1}\right)$ : Pronouns as transitive/Complex DPs}

A number of researchers have argued against the intransitive D-hypothesis. Although they do not always share the same assumptions or the same goals, they all argue for the basic thesis that (at least some) pronouns (strong, weak or clitic ones) are DPs with a complex internal structure, which involves at least two heads, and which may or may not be shared among all different pronominal types. Accordingly, two further sub-types may be distinguished within the transitive-D approach: (a) pronouns, more generally, and/or clitics in particular, are all transitive DPs, however they differ in terms of their internal structure and/or their features (this includes both differences across types and within types (as e.g. different types of clitics)) (see e.g. Cardinaletti 1994, Laenzlinger 1998, or Uriagereka 1995, Corver \& Delfitto 1993/1999); (b) all pronouns have exactly the same internal structure and/or features (e.g. Panagiotidis 2002).

Here I discuss Uriagereka (1995), who argues for a separate structure for 3rd (i.e. weak) vs. 1st and 2nd (i.e. strong) person direct object/accusative clitics in Romance languages. ${ }^{5}$ Following the insights of Postal (1969) and Torrego (1988), he argues that 3 rd person clitics are determiner heads taking a null NP complement and potentially a specifier, in which a doubled DP may occur in certain languages (see Uriagereka 1995: 81):

(3) a.

DP

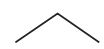

(double) D'

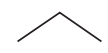

D

NP

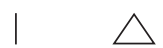

clitic pro b.

DP

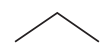

Spec D'

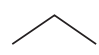

D

NP

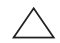

def. article lexical $\mathrm{N}$

${ }^{5}$ Uriagereka does not discuss dative clitics, however he points out (Uriagereka 1995: 87) that they are agreement heads, on a par with AgrS and AgrO (following in this Sportiche 1992/1998). 
Uriagereka argues that 3 rd person clitics move to a VP external site in order to identify pro: because they lack person features (being 3rd person determiners-see Corver \& Delfitto 1993/1999 for the licensing of pro, and Benveniste 1971 on 3rd person), they cannot license the pro NP complement on their own (contrary to strong pronouns which have person features and hence may do so). As a result, (only) clitics must target the $\mathrm{F}^{0}$ head (in those languages where $\mathrm{F}^{0}$ is active), which encodes the speaker's point of view. Since person features are standardly linked to referentiality, his claim reduces to saying that pro forces a referential reading on the determiner when the latter is related to a person bearing item. The syntactic/structural expression of this relation (i.e. movement), as well as the actual mode of movement (e.g. head movement or 'pseudo'-affixation) can be parameterized depending on the language (e.g. on whether or not $\mathrm{F}$ is present or active). Being VP-external by LF, 3rd person clitics are interpreted as specific DPs, since they fall under the Restrictive Clause of the Mapping Hypothesis.

As for 1 st and 2 nd person (strong) clitics, Uriagereka argues that they are minimal/maximal DPs which may take an adjoined doubled DP:

$$
\text { DP }
$$

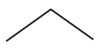

(double)

$$
\mathrm{DP} / \mathrm{D}
$$

clitic

These move/adjunction-scramble as XPs to AGRoP, from which they may further head-adjoin to $\mathrm{F}^{0}$ (in those languages where $\mathrm{F}^{0}$ is active; head-movement may be related to PF reasons). Strong clitics do not have a (null) pro, but are inherently referential due to their person features. In this way, Uriagereka can account for a number of differences between 1st/2nd vs. 3rd person clitics.

There are some problems with Uriagereka's analysis, which pose serious challenges on both theoretical and pragmatic grounds:

(a) First of all, it uses the standard arguments in favor of the postulation of a null N-pro within the clitic, namely the Extended Projection argument (see Panagiotidis 2002 and discussion below), the DP hypothesis (see Abney 1987), and the parallelism between elliptical DPs and pronominals. 
However, the Extended Projection argument does not go through. On the one hand, the Extended Projection theory, at least as formulated by Grimshaw (1991), does not require functional heads to take complements, or lexical heads to be complements of functional heads. Rather, it defines the possible combinations of functional and lexical heads on the basis of an algorithm that handles categorial features such as $\mathrm{N}$ or $\mathrm{V}$, and values thereof. Moreover, under a constructionalist realizational approach to morphology, such as e.g. Distributed Morphology, insertion of a lexical item into a functional head is possible, without requiring the presence of a lexical root. This is empirically supported by so-called light verbs, or other grammaticalized elements that do not contain any lexical (in the sense of lexical vs. functional) content. Second, the DP hypothesis proposes that determiners are separate heads projecting a functional phrase within the DP, but does not have anything to say about whether determiners do or do not take a lexical complement, since this is an independent issue. Finally, with regard to the parallelism between elliptical DPs and (strong) pronominals, although it is true that in languages like English both constructions appear to contain a covert NP (which may be the result of PF deletion, or be simply merged as such from the Lexicon, depending on the analysis adopted-see Lobeck 1995 and Merchant 1999), it is not clear whether all kinds of pronouns contain such a phrase. For example, we have already discussed some empirical evidence that no $\mathrm{N}$-head is present in weak pronouns. As a result, although theoretically speaking the postulation of the same structure for all DPs (both pronominal and non-pronominal ones) may look parsimonious in the first place, it is not always supported empirically, neither is it theoretically necessary.

Also, the null $\mathrm{N}$-pro does not seem to have the same properties in elliptical DPs and pronominals, a difference which would be unexpected under this theory: e.g. while elliptical DPs cannot take a c-commanding antecedent (i.e. they must refer to a separate entity from the one introducing the corresponding non-elided DP, behaving in this sense as an R-expression), pronouns may do so in most cases (see also Panagiotidis 2002 and Anagnostopoulou 2003b):

(5) Xtes pira ena prasino forema stin Maria ala telika to yesterday took.1sg a green dress to-the Maria, but finally it.cl jirise piso/ala telika i $\theta$ ele to kokino mprosta sti vitrina. returned.3sg back/but finally wanted.3sg the red in-front to-the window.

'Yesterday, I got Maria a green dress, but in the end she took it back to the shop/ she wanted the red one in the front of the shop.' 
In the above example, a clitic pronoun may refer back to 'the specific green dress I bought for Maria', while the elliptical DP may only refer to a different red dress that is in the front of the shop where I bought the green dress.

In addition, elliptical DPs and pronouns are subject to different licensing conditions: the former must be semantically licensed by a local antecedent (namely a DP containing an overt lexical N-head (i.e. a root)), and also formally licensed by means of an appropriate antecedent within the DP itself. Pronouns, on the other hand, may, but do not have to, be semantically/ syntactically bound (i.e. have a c-commanding (A-) antecedent), although they must be assigned a reference value via a contextual assignment (which will be extra-linguistic/discourse - centered if no semantic binding has taken place). However, pronouns do not require a formal antecedent within their structure, or if they do, as some theories have argued for some kinds of pronouns (e.g. clitics), the relevant feature involved is a lexical one ([+ human]), or, according to some analyses, a [person] feature (for 3rd person clitics -see Uriagereka 1995), specificity or referentiality, but not number or case, which are some of the typical formal features related to NP-pro licensing (see Lobeck 1991, and Alexiadou, Haegeman \& Stavrou 2007 for references):

(6) a. * the red(-s) vs. $\sqrt{ }$ the red ones vs. $\sqrt{ }$ these/that
b. * ${ }^{* a}$ vs. $\sqrt{ }$ ta kokina ('the.neu.pl vs. the.neu.pl red.neu.pl') vs. $\sqrt{ }$ afta ('these')
c. To ayorasa xtes. it.cl bought.1sg yesterday
'I bought it yesterday.'

(6a) shows that in English the elided NP may be licensed by an antecedent with number features (which are carried by one or by a determiner, since adjectives do not inflect), (6b) shows that in Greek an (agreeing) adjective is required to license an elided NP (note that it carries a full set of phi-features-see e.g. Lobeck 1991 for English, Giannakidou \& Stavrou 1999, Alexiadou, Haegeman \& Stavrou 2007 for Greek), and (6c) shows that no antecedent within the clitic phrase is required. A semantic antecedent is offered via contextual information.

(b) This approach links clitic movement to two basic factors: (a) the presence of a null NP-pro which needs licensing; (b) the lack of certain features on the $\mathrm{D}^{0}$ head, which therefore cannot license the NP-pro DP-internally. For Uriagereka the relevant feature is [referentiality] (which is ultimately linked to person). 
The main idea behind this proposal, namely that clitic deficiency is linked to clitic behavior, is intuitive and empirically promising, since it allows it to account for basic differences between strong and clitic pronouns. However, because it typically defines clitic deficiency in terms of one or more particular features, which are not necessarily shared by all clitics types, this analysis fails to predict that these types pattern on a par with respect to their syntactic position and other common properties. Uriagereka argues that movement of 3rd person clitics takes place in order to license the NP-pro, since the clitic determiner does not contain a person feature that would render pro (and therefore the whole DP pronoun) referential. ${ }^{6}$ The problem with this analysis is that there are 3rd person clitics which are not referential, but which appear in the same position as their referential counterparts. These include bound variables, expletive and predicative clitics, as well as direct object clitics used in idioms in Greek, French and other languages (see Bibis 2002 for extensive discussion). Uriagereka (1995: 88-89) (and also see Corver \& Delfitto 1993/1999) explicitly recognizes the problems posed by (some of) these clitics, however he argues that they are variables that are referentially dependent in the same way that referential and specific clitics are. Although it is true that both free and bound variables pick up their referent via a semantic assignment, it is not at all clear to me why they should involve the same syntactic derivation, namely movement to the 'point of view' $\mathrm{F}^{0}$ head. This is so, because free variables are assigned a referent via contextual assignment, a fact that could be linked to $\mathrm{F}^{0}$, if the latter is assumed to be the clausal centre of speech that interfaces LF with contextual (pragmatic) information. However, bound variables pick up their referent indirectly, via structural binding by a c-commanding antecedent (typically a determiner phrase containing a binder) whose index is assigned a referent via contextual assignment. This would mean that they would not have to establish a direct relation with $\mathrm{F}^{0}$ (assuming the latter is the syntactic expression of context assignment, not a straightforward assumption); rather the index-bearing element (i.e. the binder) would. Moreover, expletive elements may move, although they clearly do not establish any referential

\footnotetext{
${ }^{6}$ The obligatory external-VP position of clitics accounts for the fact that they are specific and that non-specific clitic determiners are impossible cross-linguistically. Note, however, that specificity cannot be related to the obligatoriness of clitic movement: clitics are definite (i.e. strong) determiners, however strong determiners do not have to move out of $\mathrm{vP}$ (overtly) in order to receive a specific/strong/familiar reading (see Corver \& Delfitto 1993/1999, de Hoop 1992, 1996, 2000 and van der Does \& de Hoop 1998, pace Diesing \& Jelinek 1995, Diesing 1996 (although see Diesing 1997: 419 ff.)). Similar remarks apply to weak determiners, which may have a strong reading even within the $\mathrm{vP}$ (although they cannot have a weak reading when scrambled/ object shifted/doubled).
} 
dependency relation; recall that according to standard assumptions in the literature expletives do not have any semantic content but merely act as PF placeholders. ${ }^{7}$ Movement may apply to both clitic and non-clitic expletives across languages. For instance, in English there may move to a higher finite clause, although it is not a clitic (presumably, movement is triggered by an EPP feature on T, which is obligatory in English—see Chomsky 1981), and the same applies to the neuter singular weak pronoun, which also moves to some higher position (see Corver \& Delfitto 1993/1999: 844 ff.):

(7) a. There seems [(there) to be a man in the room].

b. I figured it out quite easily that you didn't want to come.

Similar examples are also found with weak object pronouns in Dutch, expletive pronouns in Swedish, and with expletive clitics in Greek (for Greek see Tsakali 2006):

(8) a. Ik heb het toen betreurd dat Jan ziek was.

$I$ have it then regretted that Jan ill was

'I regretted it that Jan was ill.'

[example taken from Corver \& Delfitto 1999: 844 (their 92d)]

b. Han tar det mycket sällan $\left[_{S C} t_{s}\right.$ lugnt]

be takes it very seldom easy

'He takes it easy very seldom.'

(Swedish)

c. To iksera (to) oti o Janis ine plusios

it.cl knew.1sg (the) that the John.nom is rich

ke (to) oti i Beth ine apo tin Ameriki.

and (the) that the Beth.nom is from the America.acc

'I knew it that John is rich and that Beth is from America.' (Greek)

All these examples show that both referential and non-referential elements may move, and in fact to the same position (both for clitics/weak pronouns and non-clitics). In addition, there are referential DPs that do not move (overtly) to $\mathrm{F}^{0}$, such as e.g. strong pronouns, full DPs and weak pronouns. The same applies to strong pronouns that are interpreted as bound variables (e.g. in environments where clitics and weak pronouns are not available for

${ }^{7}$ A reviewer points out that although the standard assumption takes expletives to be semantically vacuous, this is not strictly speaking accurate, since expletives carry formal (categorial) features which are interpretable, e.g. there is a locative pronoun, it is a 3rd person singular pronoun, etc. Whether they are interpreted referentially or not has to do with the argument structure of the predicate and the element they associate with. 
independent reasons): although they appear to be referentially dependent, they do not move.

As a consequence, referentiality cannot account for all instances of 3rd person pronouns, and most importantly for the fact that they invariably appear attached on the verb in exactly the same position, even though movement to this position should be linked to referentiality. Moreover, the vP-external position of 3rd person clitics does not always entail a specific reading for them, contrary to what Uriagereka (1995) claims. Rather, specificity seems to be dependent on a combination of factors, such as the internal content of the clitic pronoun itself (e.g. on properties of its double), and the external (or internal) $\mathrm{vP}$ position in the clause. ${ }^{8}$

Problems of a similar nature occur with other types of clitics. For example, 1 st and 2nd person clitics may have referential and non-referential uses, but in both cases they appear in the same clausal position. Dative clitics appear to raise similar issues. Uriagereka argues that they are agreement markers, and hence directly merged on the extended verbal projection. The problem with this kind of approach is that it may be true for some languages, but not for all. For example, Bleam (1999) argues that Spanish dative clitics are agreement markers based on such evidence as their morphology, their obligatory presence in the dative alternation construction, and the lack of specificity effects (see also Jaeggli 1986, Roca 1992, Suñer 1988, Sportiche 1992/1998). On the other hand, in Greek, for example, dative clitics are morphologically similar to the corresponding definite determiner forms, exactly like direct clitic objects. Moreover, their presence does not correlate with the double object construction (see Anagnostopoulou 2006), and as a result their presence does not seem to be obligatory (in most cases-see Anagnostopoulou

8 That the vP-external position is involved in specifity has been shown by Diesing (1992) for both subjects and objects, but also by the empirical fact that inherently indefinite/non-specific pronouns like English one or Spanish uno (and the same holds for Greek enas) cannot be scrambled, object shifted or doubled:

(i) $\Delta$ en echo palto, ala $\theta$ a (*to) aroraso ena avrio. not have.1sg coat.acc, but fut (it.cl) buy.1sg one.acc tomorrow 'I do not have a coat, but I will buy one tomorrow.

(ii) Nei, jeg har ingen paraply, men jeg køper (*en) muligens ( $\sqrt{ }$ en) i morgen. no, I have no umbrella, but I buy (one)possibly one tomorrow 'No, I have no umbrella, but I will possibly buy one tomorrow.' [example taken from Diesing 1997: 413 (her 74-75)]

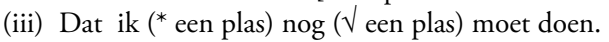
that I (a piss) still (a piss) must do 'that I still have to take a piss.'

[example taken from der Does \& de Hoop: 1998 (their 10c-d)] 
2003a, 2006 for an extensive discussion of those environments where dative cliticization is obligatory). Rather, they mark their double as topical (i.e. old information) and familiar/prominent (see Anagnostopoulou 1999, 2006), which is also the function of accusative clitics. Now, if dative clitics in Greek are not agreement markers but determiners ${ }^{9}$, it is not at all clear how Uriagereka's account could explain their movement properties and clausal position.

(c) The third major point with regard to the transitive D analysis is the issue of feature recoverability and its relation to overt clitic movement. Uriagereka argues that the pro NP complement cannot be licensed by the D-head, since the latter lacks lexical or person features (i.e. features that are presumably related to the semantic properties of the clitic, such as referentiality and $+/-$ human interpretation). Movement of the clitic to the specifier position of a head that belongs to the extended verbal projection allows the D-head (via checking) to recover the missing feature that will license pro.

Putting aside some technicality issues (such as e.g., the fact that person is uninterpretable/deletable on verbs and hence would not be expected to be recoverable to the D-head, or the fact that recoverability would lead to semantic uniformity, which however is not found empirically), the main problem with the recoverability approach is that feature recoverability cannot be uniquely linked to clitic movement. This is so, because according to this analysis recoverability depends on feature checking, which may take place either in the overt syntax or at LF (see Chomsky 1995), depending on feature strength. Assuming that recoverable features are always strong would not work, since we would expect at least some cross-linguistic variation in this regard, on a par with movement of other pronominals and DPs. Another idea, which has been used by a number of researchers, including Rizzi (1993), Cardinaletti (1994), Uriagereka (1995) and Corver \& Delfitto (1993/1999), among others, would be to argue that clitics must move overtly, because they do not contain lexical/semantic content, the latter being a prerequisite for being visible at LF.

However, there seem to be two problems with this account: first, lack of lexical content does not entail lack of semantic content. For instance, at least some clitic pronouns (and weak pronouns, more generally) may have semantically interpretable functional features (as e.g. phi-features, or deictic features for 1st and 2nd person pronouns); accordingly, at least these should be LF-visible, and hence able to move at LF (in fact, they would be required to

\footnotetext{
9 See also Joseph (1988), who argues that clitics are not agreement markers in the usual sense but may be taken instead to be transitivity markers.
} 
move at LF, given the Procrastination Principle, according to which movement that may take place at LF must take place at LF).

The second problem with this account is that in later phases of the Minimalist Program (see e.g. Chomsky 2000, 2001, 2005 and 2007) feature checking is dissociated from movement to the target/checking head. According to this analysis, long-distance Agree between a probe and a local goal within the former's c-command domain suffices to check features on both heads, and as a result movement to the minimal domain of the target (i.e. probe) is not required. If movement takes place, it is overt and attributed to a separate EPP feature. Under this analysis, the assumption that clitic pronouns do not have lexical and/or semantic content could not force overt clitic movement in all cases, contrary to fact.

\subsubsection{Subtype $\left(b_{2}\right)$ Panagiotidis 2002: a uniform transitive D approach}

Panagiotidis (2002) follows the transitive D-hypothesis, and on a par with Corver \& Delfitto (1993/1999), he applies it to all types of pronouns. However, the actual implementation of his approach differs in important respects, on both theoretical and empirical grounds. His main claim goes as follows: all pronouns, strong, weak, clitics and demonstratives have the following internal structure:

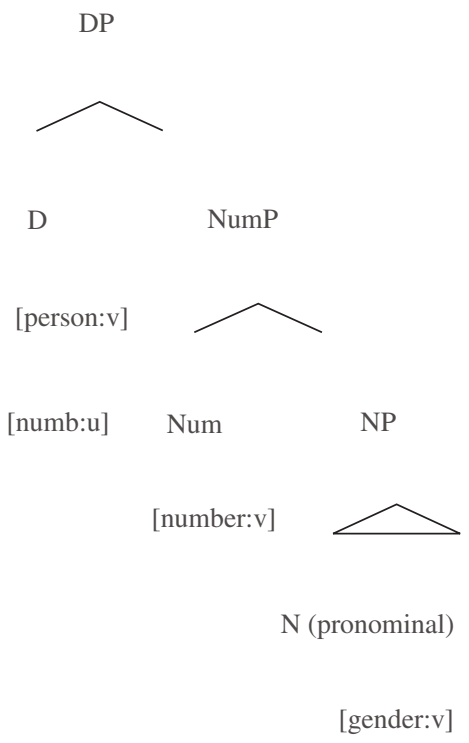

(where $\mathrm{u}=$ unvalued/uninterpretable and $\mathrm{v}=$ valued/interpretable) 
That is, pronouns are transitive determiners. The presence of particular features on particular heads follows from the assumption that LF-interpretable features must appear on certain heads cross-linguistically. ${ }^{10}$ Panagiotidis uses a number of theoretical and empirical arguments to support his proposal. For example, he argues that functional heads are typically dependent on lexical ones, possibly on phonological (depending on the given language) and abstract/syntactic grounds (they have uninterpretable categorial features that can only be checked by an appropriate lexical head), and as a result the intransitive D-hypothesis cannot be maintained. He further points out that the existence of optionally transitive determiners (such as e.g. demonstratives or plural indexicals in English - see Abney 1987) is problematic, since selection is obligatory (hence, an NP is required in all cases, even when it is covert).

For Panagiotidis, pronominal reference/pronominality derives from the fact that the null or overt $\mathrm{N}$ does not denote a lexical concept. As far as clitics are concerned, he argues that clitic movement involves two steps: (a) an XP movement step to [Spec, AGRoP] (for case checking); and (b) a local $\mathrm{X}^{0}$ movement step to a higher functional head (e.g. T) (following a quite standard approach in the literature-see Sportiche 1990). He points out that a complex DP approach can capture this derivation in a principled fashion. Moreover, it is conceptually more adequate than a $\mathrm{D}^{0} / \mathrm{DP}$ analysis, since it allows different types of features to be interpreted at specific points within the clause (phifeatures at [Spec, AGRoP]; specificity/topic-hood at T). This is so, because the $\mathrm{D}^{0}$-head, which contains definiteness/person, but not phi-features, moves out of the DP in the second $\mathrm{X}^{0}$-step.

Panagiotidis's approach seems to be the least able one to account for the differences found across pronominal types, given that he postulates a single structure for all types (as well as for certain types of DPs). Since, according to current theorizing, variation in structure (presumably, in terms of features, on the basis of which structure is projected) reflects variation in the actual syntactic/semantic behavior of syntactic constituents, Panagiotidis's uniform approach would predict that no such differences should exist among pronouns, which is obviously not true, both for Greek, but also for other languages (see, for instance, the discussion in Cardinaletti \& Starke 1999).

Panagiotidis argues that clitic movement takes place stepwise, each step being related to some (separate) feature or property $\mathrm{P}$ that is not present in strong and only partially present in weak pronouns. However, there are some problems with this kind of approach. First of all, it fails to be explanatory in two ways: (a) it does not really solve the problem of the syntactic distribution

\footnotetext{
${ }_{10}$ This does not prevent uninterpretable counterparts of the same features to be located on other heads.
} 
of pronominals; rather, it restates it by simply postulating two arbitrary features/properties, which need further motivation and investigation, not an easy task at all, taking into consideration the failure of such features as 'specificity', 'topicality', 'case', 'person', 'referentiality', which have been widely used for the same reason in the past literature. As a result, unless we find a principled way to isolate and motivate these extra features that are only specific to some types of pronouns (at least in some languages), any attempt to attribute the special properties of weak and clitic pronouns to such features will be vacuous; (b) it does not explain how the 'addition' of the same extra features to the common pronominal structure, triggering in this way the same two steps, seems to be found in so many different languages. This might, in fact, suggest that these features/properties are so central to cliticization, that they should be considered as permanent features of the pronominal structure of clitics and weak pronouns. Essentially, this would mean that clitics and weak pronouns do not have the same structure with strong pronouns, contrary to Panagiotidis's original hypothesis.

The difference between pronouns/elliptical DPs and full DPs with regards to the possibility of taking arguments is also problematic. The main reason is that, empirically speaking, such a difference is not absolute, since there are languages where (some) pronouns and elliptical DPs may take an argument. For example, Ticio $(2003,2005)$ argues that cliticization out of complex DPs in Spanish is allowed under certain structural (locality) conditions, even in the presence of argumental DPs. An example is given below (e stands for the base/ first merge position of the clitic):

(11) Vendimos $\left.[\text { los libros [de Cervantes }]_{a g}\right]$ y $\operatorname{los}_{\mathrm{i}}$ compramos $\left[\mathrm{e}_{\mathrm{i}}[\mathrm{de}\right.$ Chomsky $]_{\mathrm{a} a}$.

We-sold the books of Cervantes and cl we-bought of Chomsky

'We sold the books by Cervantes and we bought the ones by Chomsky.' [adapted from Ticio 2005: 280 (her (95))]

The same sentence is ungrammatical in Greek (unless the clitic doubles the DP, in which case it is not covert), ${ }^{11}$ even though extraction out of DPs is possible in principle:

11 The relevant sentence would appear as Pulisame ta vivlia tu Cervantes ke ta arorasame ta vivlia tu Chomsky, although in this case the contrastive focus reading, which is found in elliptical DPs, would not be available. As a reviewer points out, the reading where there is a contrast between pulisame and arorasame is ungrammatical; the sentence can only be acceptable as two different sentences (e.g. first we did this (sold x) and next we did that (bought y)). 
(12) a. * Pulisame ta vivlia tu Cervantes ke ta ayorasame tu Chomsky.

Sold.1pl the books.acc the Cervantes.gen and them.cl bought.1pl the Chomsky.gen

'We sold the books by Cervantes and we bought the ones by Chomsky.'

b. TA VIVLIA pulisame tu Chomsky, ochi ta arӨra. THE BOOK sold.1pl the Chomsky.gen, not the articles.acc 'It is the books of Chomsky that we sold, not his articles.'

On the other hand, demonstrative pronouns do co-occur with argument DPs in Greek, ${ }^{12}$ and the same applies to (definite/indefinite) elliptical DPs: ${ }^{13}$
$\Delta$ en vrika
tin kokini tsanta
tis Marias
ala $\theta$ a paro tin $\mathrm{mble} / \mathrm{mia}$ tis Sulas.

12 Note that in reality these constructions do not involve a demonstrative pronoun containing a covert noun. Rather, as it has been discussed quite extensively in the literature (and see Giusti 1997 and Alexiadou, Haegeman \& Stavrou 2007 for more details and references), demonstratives and 1st and 2nd person pronouns are maximal projections that may be merged in a specifier position within some larger DP. Similar remarks apply to indefinite quantifiers, although there is a high chance that these appear in some lower position within the DP. An approximation of the relevant structure is given below (for evidence against N-movement to a higher position in Greek see Alexiadou 2001):

(i) $[\mathrm{DP}[\mathrm{DP}$ afto] [D' [D to] [XP kokino [X' [YP afto [NP forema [DP tis Maras]]]]]]]

(ii) [DP [D' [XP merika [YP kokina [NP vivlia [DP tis Maras]]]]]]

The corresponding English construction would be as follows:

(iii) $\left[\mathrm{DP}\left[\mathrm{D}^{\prime}\left[\mathrm{D}^{0}\right.\right.\right.$ those] [XP friendly [NP students [DP of Physics]]]]]

This structural difference does not change the argument, given that in both languages the $\mathrm{N}$-head would be covert (i.e. an empty pronominal noun would be merged):

(iv) $\sqrt{ }\left[\mathrm{DP}\left[\mathrm{DP}\right.\right.$ afto] [D' [YP afto [NP [ $\left[\mathrm{N}^{0} \mathrm{E}_{\mathrm{N}}\right][\mathrm{DP}$ tis Maras]]]]]

(v) $\sqrt{ }\left[\mathrm{DP}\left[\mathrm{DP}\right.\right.$ emis] [D' [NP [ $\left.\mathrm{N}^{0} \mathrm{E}_{\mathrm{N}}\right][\mathrm{DP}$ tis fisikis]]]] ('we (students) of Physics')

(vi) * [DP $\left[\mathrm{D}^{\prime}\left[\mathrm{D}^{0}\right.\right.$ those $]\left[\mathrm{NP}\left[\mathrm{N}^{0} \mathrm{E}_{\mathrm{N}}\right][\mathrm{DP}\right.$ of Physics $\left.\left.\left.]\right]\right]\right]$

${ }_{13}$ The same appears to be true also for indefinite drop constructions, although the result may sound less acceptable than when the relevant DPs have an overt indefinite determiner:

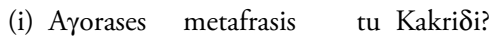

bought.2sg translations.acc the Kakridi.gen

'Did you buy translations made by Kakriois?'

?? Oxi, ala ayorasa tu Seferi.

no, but bought.1sg the Seferi.gen

'No, but I bought translations made by Seferis.' 
Not found.1sg the red purse.acc the Mary.gen but Fut take.1sg the bluelone.acc.fem the Sula.gen

'I did not find Mary's red purse but I will take Sula's blue one/one from Sula instead.'

(14) a. Kita afta tis Sulas!

Look.2sg these.pl.neuter the Sula.gen

'Look these ones that are Sula's.'

b. Kratisa merika/kapja/ena tu Kosta.

kept.1sg some.acclone.acc the Kosta.gen

'I kept some/one that belonged to Kostas.'

English, on the other hand, does not allow argument DPs, neither with overt nor with covert pronominal nouns:

(15) a. * You will meet the ones of Physics.

b. * Take those/some/one of John.

c. ${ }^{*}$ I will buy it of Chomsky.

If all these pronouns and DPs contain a null pronominal noun with no lexical content, and if such a noun cannot license argumental DPs, it is not clear how the differences noted above between Greek, Spanish and English would be accounted for in the first place. If we would like to stick to this analysis, we would either have to assume that $\mathrm{E}_{\mathrm{N}}$ may differ in its properties across languages or across structures within a single language (cf. demonstratives and clitics in Greek), or, alternatively, that each case should be analyzed differently (both within and across languages). In any case, we would be led to conclude that not all kinds of pronouns and elliptical DPs share exactly the same structure, a conclusion which is against the basic tenet of Panagiotidis's analysis, and which shows that adherence to a parallel structure for all these constructions is not empirically tenable.

Another problem that Panagiotidis's approach faces is that it cannot predict in a principled way the correlations that appear to exist between different types of properties (i.e. properties of different grammatical levels) that have been observed both within and across pronominal types (see Anagnostopoulou $2003 \mathrm{~b}$ for this argument). In addition, if the main arguments used to argue in favor of Panagiotidis's approach can be refuted, and the common properties shared among pronoun types be accounted for by these other approaches, then the 'same structure for all pronouns' approach would have to be abandoned. This is what I am going to discuss below.

Panagiotidis makes the following points with regard to the existence of $E_{N}$ and its properties: 
(a) Pronominality, namely the fact that pronouns are interpreted as semantic variables at LF and beyond and hence do not denote a concept, is due to the presence of an empty pronominal noun, $\mathrm{E}_{\mathrm{N}}$, which is a noun without semantic content.

(b) The existence of overt empty/grammatical nouns $\mathrm{E}_{\mathrm{N}}$ (i.e. nouns with formal/functional features only), such as one in English, supports the existence of a null counterpart, both in English (cf. those vs. those ones) and in other languages in which $\mathrm{E}_{\mathrm{N}}$ may never appear overtly.

(c) Pronouns encode gender cross-linguistically; since gender has been independently shown to be an inherent property of $\mathrm{N}$ (given that it is a derivational feature) and under the assumption that LF-interpretable features only appear on certain heads cross-linguistically, it follows that also pronouns must contain an $\mathrm{N}$-head encoding gender.

Most, if not all, of these arguments can be refuted quite easily, which would make Panagiotidis's analysis much more problematic. For example, with regards to point (a) Panagiotidis himself admits that $E_{N}$ is not a necessary condition for pronominality: in his analysis of null subjects he argues that pro does not exist and that AGRs is split into a $\mathrm{D}\left({ }_{\mathrm{V}}\right)$ head and Numb head. Moreover, no $\mathrm{E}_{\mathrm{N}}$ head is present, however this does not prevent $\mathrm{D}_{\mathrm{V}}$ from being interpreted pronominally, which clearly shows that pronominality cannot be used as an argument in favor of the presence of $\mathrm{E}_{\mathrm{N}}$ in other pronominal elements. If the semantic variable interpretation of pronouns does not stem from $\mathrm{E}_{\mathrm{N}}$, the latter ends up having no LF effect, and since it does not have a PF effect either (for obvious reasons), there should be no reason for its existence in minimalist terms. In order to deal with this problem, Panagiotidis argues that there is some other LF role for $\mathrm{E}_{\mathrm{N}}$ : it semantically denotes a (trivial) open predicate of type $<\mathrm{e}, \mathrm{t}>$, which saturates a determiner (which is of type $<<$ e,t> e>) (see Higginbotham 1985, Heim \& Kratzer 1998 for discussion). Although this is generally true, it has been independently argued for in the literature that pronouns are of type $<\mathrm{e}>$, which would make the semantic contribution of $\mathrm{E}_{\mathrm{N}}$ dubious. A possible counterargument is that the correlation between $\mathrm{D}$ and $<\mathrm{e}>$ in pronouns in the semantic literature basically stems from the assumption that pronouns are syntactically intransitive $\mathrm{D}^{0}$-heads. If there were independent arguments in favor of a complex syntactic structure, the interpretation of D as of type <e> would be problematic, since under standard assumptions regarding functional application, the meaning of the whole DP pronoun (i.e. $<$ e $>$ ) would be the result of the meanings of the elements that make up the pronoun plus the meaning of their (mode of) combination. This would render the interpretation of $\mathrm{D}$ as $<\mathrm{e}>$ rather unlikely (unless one assumed that all other sub-constituents of the pronoun are also of type <e> 
and their combination would be a function that takes <e> type elements as arguments and yields <e > type constituents).

With regards to point (b), although there are indeed languages which have overt pronominal nouns, such as e.g. English one or Japanese kare (see Déchaine \& Wiltschko 2002 and Panagiotidis 2002), and possibly covert ones, it does not necessarily follow from that, that such a noun should be available in all languages, even in those which do not offer phonological evidence for it. For instance, English appears to have an overt empty/ grammatical noun, one, and possibly also a covert one, at least according to a non-deletion approach to ellipsis (see Lobeck 1995), as shown in the following examples:

(16) this one vs. this $\square$

Panagiotidis assigns the following structures to the DPs in (16), following proposals by Postal (1969):

$$
\left.\left[\mathrm{DP}\left[\mathrm{D}^{0} \text { this }\right]\left[\mathrm{NP}\left[\mathrm{N}^{0} \text { one }\right]\right]\right] \text { vs. [DP }\left[\mathrm{D}^{0} \text { this }\right]\left[\mathrm{NP}\left[\mathrm{N}^{0} \square\right]\right]\right]
$$

According to Panagiotidis, both one and $\square$ are $\mathrm{N}^{0}$-heads, with which $\mathrm{D}^{0}$ agrees. In this respect, the syntax of DPs containing such empty $\mathrm{N}^{0}$-heads parallels that of DPs with lexical (non-closed class) $\mathrm{N}^{0}$-heads. However, in English there seems to be syntactic evidence in favor of a zero $\mathrm{N}^{0}$-head in constructions like those in (16) and (17). For example, a restrictive relative clause can modify (most) personal pronouns or demonstratives:

(18) a. He who must not be named gave orders to the Death Eaters.

b. She who must be obeyed has made her entrance. (example taken from Elbourne 2005: 120 (his 114))

Moreover, personal pronouns may be followed by an overt lexical N-head (although there are also some restrictions depending on person/number):

(19) a. We men

b. You linguists.

c. You (men) who wish to escape.

d. You here.

In Greek, on the other hand, only strong pronouns and full nouns may be modified by a (restrictive or non-restrictive) relative clause:

(20) a. Milisa me esena pu ise ylosoloyos. talked.1sg with you.str that are.2sg linguist 'I talked to you who are a linguist.' 


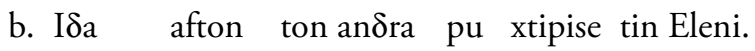
saw.1sg him.str the man.acc that hit.3sg the Eleni.acc 'I saw the man that hit Helen.'

c. I $\delta$ a afton pu xtipise tin Eleni. saw.1sg him.str that hit.3sg the Helen.acc 'I saw him who hit Helen.'

The same sentences are ungrammatical with clitic pronouns, unless they double a DP:

(21) a. ${ }^{*} \mathrm{Su}$ milisa pu /o opios ise $\gamma$ losoloyos. (Greek) you.cl talked.1sg that/the who.nom are.1sg linguist

'I talked to you who are a linguist.'

b. ${ }^{*}$ Ton i $\delta \mathrm{a} \quad \mathrm{pu} / \mathrm{o}$ opios xtipise tin Eleni. ${ }^{14}$ him.cl saw.1sg that/the who.nom hit.3sg the Helen.acc

'I saw him who hit Helen.'

c. Su milisa esena pu/o opios ise $\gamma$ losoloyos. you.cl talked.1sg you.str that/who are.2sg linguist.nom 'I talked to you who are a linguist.'

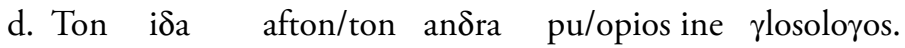
him.cl saw.1sg him.str/the man.acc that/who is linguist.nom 'I saw him/ the man who is a linguist.'

Also, clitics cannot be followed by an $\mathrm{N}^{0}$-head, contrary to strong pronouns (unless, again, they double a DP):

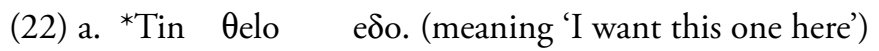

her.cl want.1sg here

'I want this one here.'

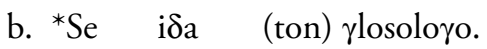

you.cl saw.1sg the linguist.acc

'I saw you the linguist.'

${ }^{14}$ A reviewer correctly points out that the verb $i \delta a$ followed by $p u$ can give rise to a pseudorelative construction (ton $i \delta a$ pu xtipise tin Eleni = I saw the event that involved $\mathrm{x}$ hitting Helen). When the clitic is present only the pseudorelative construction is available (hence the absence of a relative pronoun). If there is a strong pronoun, then either a relative or a pseudorelative reading is possible (cf. (20c): I saw him/the person who hit Helen, or I saw him hitting Helen). The pseudorelative is due to the presence of a perception verb. If another verb is chosen (e.g. meet) then the pseudorelative reading does not arise. 


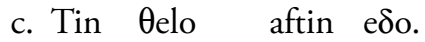

her.cl want.1sg her.str here.

'I want this one here.'

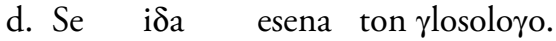

you.cl saw.1sg you.str the linguist.acc

'I saw you the linguist.'

Interestingly enough, the English pronoun $i t$, which has been argued by many linguists to be a weak pronoun (cf. Corver \& Delfitto 1993/1999 and Cardinaletti \& Starke 1999, and the following examples: V give it away vs. * give away it, // $\sqrt{ }$ It is him that I like vs. * It is it that I like), is also ungrammatical with a relative clause or a following N-head (see also Elbourne 2005):

(23) a. * It that rolls fastest gathers no moss.

b. ${ }^{*}$ It which rolls fastest gathers no moss.

c. That which rolls fastest gathers no moss.

d. Those who hesitate are lost.

(all examples taken from Elbourne 2005: 121 (his 116))

(24) *I want it here.

Finally, note that in Greek a bare definite article behaves on a par with clitics and weak pronouns, as opposed to the indefinite article, and contrary to what is the case in Romance. In English, a bare definite determiner without one is also ungrammatical:

(25) a. ${ }^{*}$ E $\gamma o$ i $\delta$ a tin pu filise o Kostas.

I saw.1sg the.acc that kissed.3sg the Kostas.nom

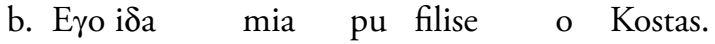

I saw. 1sg one.acc that kissed.3sg the Kostas.nom

c. Quiero la que Juán quiere.

Love.1sg the that John wants.3sg

'I love the one that John loves.'

d. The ${ }^{*}$ (one) who hesitates is lost. (taken from Elbourne 2005: 122 (his 120))

These data are quite revealing. As far as relative clause modification is concerned, it is obvious that in Greek an overt $\mathrm{N}^{0}$-head is possible with modification. Strong pronouns are also compatible with modification, supporting in this way Panagiotidis's analysis that pronouns contain a (covert) nominal head. However, clitics are not grammatical with it, which renders his uniform 
approach to the internal structure of pronouns rather problematic: given that $\mathrm{E}_{\mathrm{N}}$ has the same features in both strong and clitic pronouns, it is not clear to me why clitics would not allow modification of their covert empty noun. On the other hand, a theory that would postulate an $\mathrm{N}^{0}$-head for strong pronouns only would naturally account for this difference.

One of Panagiotidis's major arguments in favor of the presence of an empty lexical $\mathrm{N}^{0}$-head for all pronouns and elliptical DPs is based on the presence of gender on 3rd person pronouns. His argumentation goes as follows: it has been convincingly shown in the literature (see Corbett 1991, Ralli 2002, Ritter 1993, among many others — and see Alexiadou, Haegeman \& Stavrou 2007 for extensive references) that gender is an inherent lexical property of $\mathrm{N}^{0}$-heads that has to be learned separately for each (gender carrying) lexical item. Moreover, as Panagiotidis argues, gender cannot be a feature on determiners, given that, on the one hand, gender agreement is possible on determiner-less adjectival phrases, while, on the other hand, gender is also found in languages with no overt articles (such as Slavic languages). These facts, combined with his theoretical assumption that interpretable features are found on specific heads, support the hypothesis that pronouns, and more generally any nominal with no overt $\mathrm{N}^{0}$-head, contain a grammatical/empty noun with inherent gender features. Accordingly, gender agreement on adjectives, determiners or other heads within the DP is the spell-out of an uninterpretable feature on these heads that has been valued via Agree (in the sense of Chomsky $2000,2001)$ from the interpretable gender feature on $\mathrm{N}^{0}$.

Although gender marking on pronouns is among the strongest arguments in favor of the postulation of a covert $\mathrm{N}^{0}$-head in their structure, it nevertheless faces a number of problems. First of all, it seems to be too rigid in that there are languages where gender is not a property on $\mathrm{N}^{0}$ (see Anagnostopoulou 2003 b on this argument). Ritter (1993), for example, argues, quite convincingly, that a number of differences in the properties of nouns in some Romance languages and in Hebrew can be accounted for adequately if one takes gender to be specified on $\mathrm{Numb}^{0}$ vs. $\mathrm{N}^{0}$ respectively. If Ritter is correct in her analysis, then not all pronouns in every language would need an empty $\mathrm{N}^{0}$-head due to gender marking. And, since according to Panagiotidis's approach intepretable features on separate heads do not interact with each other, it is not clear to me how his analysis would capture the fact that, for instance, in Hebrew gender does not interact with number, as opposed to Spanish where it does.

A second problem with the assumption that gender may only be specified on $\mathrm{N}^{0}$ is that there are cases where gender is not an inherent property of $\mathrm{N}^{0}$. For example, Alexiadou (2004) and Ralli (2002), among others, argue that in a set of nouns in Greek (mainly those ending in -os which denote professions) 
the nominal stem as well as the nominal (declension) affix -os are underspecified for gender (i.e. they have no inherent value for it), the specification for the latter being assigned at the phrasal level by the determiner:

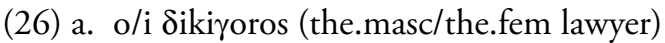

b. O Mitsos /I Roksani ine riatros. the.masc Mitsos.nom.masc/the.fem Roksani.fem is.3sg doctor 'Mitsos/Roxani is a doctor.'

In this case, the gender feature on the determiner cannot be uninterpretable, as it would be impossible for it to get valued from the gender feature on $\mathrm{N}^{0}$ (given that the latter does not have a value). We may conclude two things from these cases: (a) gender on $\mathrm{N}^{0}$ does not always come with a value from the Lexicon; (b) gender on $\mathrm{D}^{0}$ may be inherent and interpretable. Accordingly, the presence of gender on a pronoun would not necessarily mean that the latter must contain an empty $\mathrm{N}^{0}$-head.

Although the link between gender and $\mathrm{E}_{\mathrm{N}}$ is not as straightforward as Panagiotidis would like it to be, it is nevertheless true that gender is an inherent property of nominal elements (see Chomsky 1995 and Corbett 1991, 2006). Moreover, although gender may be inherent or non-inherent, nevertheless, when inherent, it may only appear on some constituent that is nominal in terms of syntactic category. Namely gender appears to be contingent on the presence of some nominal feature in the structure. Consequently, if we assume that $\mathrm{E}_{\mathrm{N}}$ is not present in pronouns, the presence of gender (and possibly other inherent nominal phi- features, such as person and number) would remain unexplained and largely coincidental, which is counter-intuitive, given that gender co-occurs with person and number on nominal constituents quite systematically. This is the essence of the empirical side of the Extended Projection issue Panagiotidis points out with regard to the bare DP analysis of pronouns. We could follow Marantz $(2001,2006)$ and assume that categorial status is not an inherent property of lexical heads, but rather is syntactically assigned via special phase heads, which are merged with (appropriate) lexical roots that are not specified for category. According to this theory, a noun would be derived by merging a lexical root with a functional nominalizer head $n$. The outcome of this merger would be sent to Spell Out, ensuring that whatever merges next will have to contain features that make it compatible with the complex n-root-head. These could possibly include nominal/categorial features, capturing in this way the notion of Extended Projection. ${ }^{15}$ According to

\footnotetext{
${ }^{15}$ Following a root-nominalizer approach, an Extended Projection would be formed by means of a series of heads related with each other via c-selection. The latter would be technically
} 
this approach, then, category defining heads such as $v^{0}, n^{0}$ and $a^{0}$ (where $a^{0}$ stands for adjective) have a special status in a number of respects (syntactic, morphological, categorial, semantic) (see Marantz 2001, 2006 for extended discussion). Since gender is cross-linguistically an inherent feature of nouns, and since a noun may only be derived by means of an $n$-head (i.e. roots are not specified for category, and hence would not be expected to be specified for gender), it follows that $n^{0}$ would also carry the gender feature. Accordingly, gender would not be dependent on a lexical root, but rather on the presence of a functional nominal head.

Two questions arise from the above discussion: (a) if gender is a feature on a nominalizer head, how can we capture the fact that in purely morphological terms gender may be dependent on the lexical stem, rather than e.g. the inflectional class of the endings added to the stem? (see e.g. Ralli 2002, 2003 for arguments that gender in Greek is an inherent property of lexical stems); (b) 'shift' of gender to a functional nominalizer head leaves the empty $\mathrm{N}^{0}$-head in pronominals (and possibly in elliptical DPs) without LF-support, however it is not at all clear that it can capture the structural differences that can be observed among the different kinds of pronouns and DPs (and which were discussed above-cf. e.g. modification by a relative clause, or by an $\mathrm{N}^{0}$-head), since according to this analysis all pronouns would end up with a nominalizer, but with no (empty) root head.

With regard to point (a), one could argue that the actual value of the gender feature on the nominalizer is specified upon its merger with a root. The value could be the function of the semantic properties of the root (e.g. in those cases where gender is defined on the basis of such features as animacy/human-see Corbett 1991), or simply the result of some arbitrary convention (i.e. as an inherent property of the nominalizer-root combination). In both cases gender would be viewed as a 'lexical' property, since it would be negotiated within the root domain. Moreover, note that the lexical stem (i.e. the root in Distributed Morphology terms) is only one of the possible factors that define gender. For example, Ralli $(2002,2003)$ has convincingly shown that in Greek derivational affixes specify the value of the gender of the whole word. These affixes realize the nominalizer head, giving direct support to the assumption that the latter hosts the gender feature.

With regard to point (b), we could argue that strong pronouns and elliptical DPs have a (covert) lexical root, as opposed to weak pronouns that do not. Although this hypothesis may seem rather ad hoc, and moreover it forces us to

derived via merge/agree between these heads on the basis of categorial features (see Julien 2002, Panagiotidis 2002, Matushansky 2006, and references therein, for this analysis). 
abandon the analysis of pronominality in terms of an empty pronominal $\mathrm{E}_{\mathrm{N}}$, on the other hand there seems to be some evidence in favor of it. For one thing, 3rd person strong pronouns in Greek can be decomposed into a stem (root) ${ }^{16}$ which remains constant, and a set of endings which change shape depending on the set of phi-features expressed ${ }^{17}$ :

(27) aftos, aftu, afton, afti, afton, aftus (he.sg, his.sg, him.sg, they.masc, etc.) afti, aftis, aftin, aftes, afton, aftes (she.sg, her.sg, her.sg, they.fem, etc.) afto, aftu, afto, afta, afton, afta (it.sg, its.sg, it.sg, they.neut, etc.)

3rd person clitics, on the other hand, lack the invariant morpheme, and only contain the inflecting part, which denotes gender, person and number distinctions. Even though one could argue that the clitic contains a null root (instead of an overt one), it would not be clear why clitic pronouns typically lack an overt morphological stem across different languages. Moreover, the postulation of such a difference between strong and clitic pronouns would account both for the presence of gender on both pronominal kinds as well as for the lack of structural evidence in favor of an empty root in clitics.

Note, however, that a similar analysis is not as straightforward for 1st and 2nd person strong pronouns. For example, Ralli (2000) points out that eyo ('I.nom.sg') does not seem to be amenable to a morphological decomposition into a stem and an inflectional ending. Drachman (1997), on the other hand, analyzes the same form as $e-\gamma o$, where $e$ - is the stem (and the same applies to other 1st person types, namely e-mas, e-mis, and 2nd person types, such as e-si, $e$-sas, etc.). Even if a stem-inflectional ending decomposition of all strong pronouns is not possible, we could take these forms to have a null $\mathrm{N}^{0}$-head.

Elliptical DPs could also be analyzed as containing a nominalizer and an empty lexical root. This is supported by the fact that such DPs have the same s-selectional restrictions with DPs containing an overt lexical $\mathrm{N}^{0}$-head. To illustrate, in the following example,

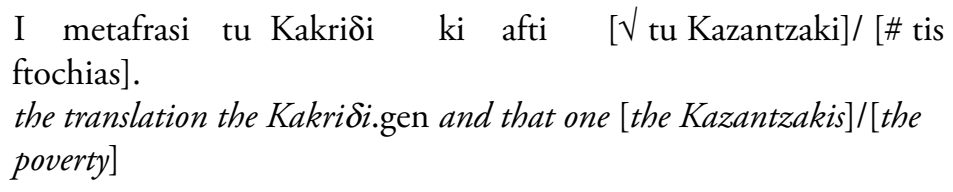

the second conjunct, which consists of a 3 rd person strong pronoun and a genitive DP argument (which is possible in such constructions in Greek, as

\footnotetext{
${ }^{16}$ For the relation between stem and root and the status of stem in Greek as the basis of words see Ralli (2003).

${ }^{17}$ See also Joseph (2001) for argumentation that speakers perceive the weak pronoun ton as the strong pronoun afton minus initial af, leading to the analogical formation of nominative tos.
} 
opposed to English, presumably for independent reasons; for genitive arguments within the DP in Greek see Alexiadou 2001, Alexiadou, Haegeman \& Stavrou 2007), is acceptable only if the non-elided DP is semantically compatible with the lexical $\mathrm{N}^{0}$-head of the first conjunct. One way to capture this fact would be to analyze the second conjunct as containing a null $\mathrm{N}^{0}$-head which copies the lexical content of the $\mathrm{N}^{0}$-head in the first conjunct. The exact nature of this $\mathrm{N}^{0}$-head (whether e.g. it is an empty lexical head, or involves PF-deletion) and the copying/licensing process itself are not important here. Rather, what matters is that an elliptical DP without a lexical root would be predicted to impose no semantic restrictions on the DP argument. ${ }^{18}$

All in all, it seems that gender on clitics, strong pronouns and elliptical DPs does not necessarily force the presence of an empty $E_{N}$ in all these constructions. On the contrary, there is some evidence that weak pronouns do not contain a null root/stem, while on the other hand a theory decomposing the traditional $\mathrm{N}$ into a nominalizer and a root can capture the structural differences but also the other similarities and/or differences between pronominal kinds in a more adequate way.

If all these arguments can be decomposed, and if Panagiotidis's theory is both too strong and too weak in empirical respects (in the sense that on the one hand it overgeneralizes, while on the other it may be too restrictive), we can safely conclude that the hypothesis that all pronoun types have one uniform structure cannot be maintained on empirical and theoretical grounds.

\section{A dynamic approach to the structure of personal pronouns}

In this section, I propose my own analysis of the internal structure of clitic pronouns in Greek. A plausible idea could be that the clitic starts off as a $\varphi \mathrm{P}$

18 Interestingly enough, clitic pronouns may allow coercion of predicates into a metaphorical reading, which is not possible with strong pronouns and full DPs. For example, the verb anapodoririzo ('to turn upside down') receives a literal reading which involves a [+/- animate] theme:

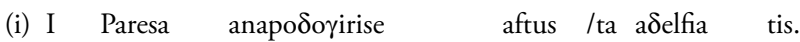
The Paresa.nom turned-upside-down.3sg them.str/the siblings.acc his.cl

'Paresa turned them/her siblings upside down.' (literal reading)

However, a clitic alongside the literal reading also allows a coerced non-literal/metaphorical (psychological) reading:

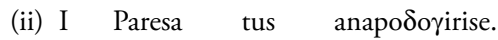

The Paresa.nom them.cl turned-upside-down.3sg

'Paresa upset them (metaphorical) /turned them upside down (literal).' 
(see Déchaine \& Wiltschko 2002 or Cardinaletti \& Starke 1999) but only becomes a DP when it reaches its verbal host, i.e. $v^{*}$-T. More particularly, the clitic would merge with a $\mathrm{D}$-head/feature in the $\mathrm{v}^{*}$-T position, becoming a proper $\mathrm{D}$ head. The $\mathrm{D}$-head/feature in this position would be related to [-focus]/topicality, accounting for the derived scope of cliticization in Greek (see Mavrogiorgos 2009 for more details). Although this is quite an insightful idea and one which I use later on, the main problem with it as it stands here is that the clitic and the doubled DP do not share the same features although they are in an agreement chain (see Suñer 1988). This is so, since the clitic is a $\varphi \mathrm{P}$, while the doubled phrase is a DP. This means that as long as DPs get doubled by clitics, the latter cannot be $\varphi P s$; rather, they must be DPs, so as to match their doubled DPs in features. ${ }^{19}$

So, how to proceed? Here, I follow two general approaches, namely the dynamic approach to pronoun construction and the fragmentation approach to pronoun construction. According to the dynamic view, pronouns are

\footnotetext{
Although it is not entirely clear to me why only a clitic pronoun allows semantic coercion, one plausible hypothesis would be to link this possibility to the lack of any lexical/root content in the clitic. A further possibility, suggested by a reviewer, would be to attribute this property to the status of clitics as inflectional elements.

${ }_{19}$ A reviewer points out that doubling of an object DP by a clitic $\varphi P$ should not be a problem given that agreement involves non-distinctness of features rather than identity thereof. Moreover, at least in languages like Greek, DPs can also be doubled by the agreement affix on the verb. Note, however, that agreement between a (direct object) clitic and its doubled DP does not seem to fall under the standard agreement relation as defined in Chomsky (2001a), in that nondistinctness is not sufficient to capture the observed correlations. For example, non-distinctness would predict that the clitic and its double could differ in their definiteness values or their specificity values, which is nevertheless not possible, as Suñer (1988) has pointed out. This 'rigid' type of agreement would be better captured if we assumed that the clitic is an optional topicalizer/ determiner merged in the left periphery of the doubled DP, encoding familiarity/prominence/ topicality, and sharing formal features with a lower determiner which encodes definiteness (see Mavrogiorgos 2009 for more details). The clitic would be probed by the clausal $\mathrm{v}^{*}$ head, leading to clitic movement to $\mathrm{v}^{*}$ (and subsequently to incorporation). For indirect clitics (which are not sensitive to the definiteness restriction) we would have to assume that the two determiners do not need to share formal features, either because the clitic is not generated within the doubled DP in the first place, or simply because the indirect object determiner does not have a definiteness feature. Finally, as for the fact that in Greek DPs can be doubled by the agreement affix on the verb, note that it is not clear whether this is a true doubling case or rather an instance of Chomsky-agreement. If it is the second, then non-distinctness (and hence a featural subset relation) is expected. If, on the other hand, it is the first one, we would have to assume that the agreement affix contains a D-feature, a quite natural thing to assume given that the subject agreement affix in Null Subject languages has been argued to satisfy the EPP/D-feature on T (see Alexiadou \& Anagnostopoulou 1998). In any case, it would not create a problem for the 'rigid' agreement Suñer (1988) first proposed for doubling constructions in Spanish and other languages.
} 
constructed on line out of features/heads, which are combined together by the derivational system in the spirit of Kratzer (2009). The fragmentation view, on the other hand, argues that for example direct object clitics are subject to distinct restrictions from indirect object clitics both within and across languages and as a result they should be analyzed separately.

Starting from direct object clitics, I assume that 3rd person clitics have gender features as their basis. Gender is number neutral, it denotes a property, and it is a descriptive feature. Syntactically it resides in the nominalizer $n,{ }^{20}$ and on its own it cannot form a pronoun, since it is of type $<e, t>$. Gender combines with number, which is an operator, with its own syntactic projection, as well as with [def] which resides in D. [Def] turns it into a definite description, therefore into type <e>, and hence into a proper pronoun. In other words, 3rd person clitics do not have any lexical content (root), they only have AgrN (i.e. $\mathrm{n}$ and numb) and D.

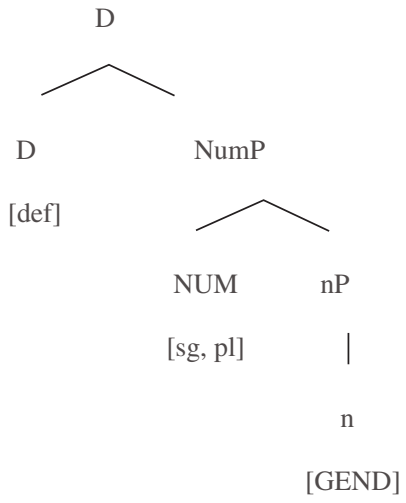

As for 1 st and 2 nd person clitics, I assume that these have participant features, 1 st and 2 nd person, which are of type <e>, therefore they cannot combine with [def]. As a result, they are directly referential, referring to the speaker and hearer, respectively. They may also contain the group feature, and/or number, although not gender, since gender cannot combine with features such as speaker/hearer (the result would be a pronoun of type $<\mathrm{t}>$ ). Number does not project a phrase on its own; rather, it combines with person to give the interpretation of the intersection of two sets, namely the set of number and the

${ }^{20}$ According to a reviewer the analysis of 3rd person clitics as of category $n$ is reminiscent of the analysis of Manzini \& Savoia who treat (singular) 3rd person clitics as N, while they take 1st and 2 nd person clitics to be Person (where the number distinction is not always relevant). 
set of person (see also Anagnostopoulou 2003a: chapter 5). As Kratzer herself points out (see Kratzer 2009: 222), morphophonological reasons may require that 1 st and 2 nd person pronouns are Ds, even though they do not require a [Def] feature semantically. In that case they would also end up being DPs. ${ }^{21}$

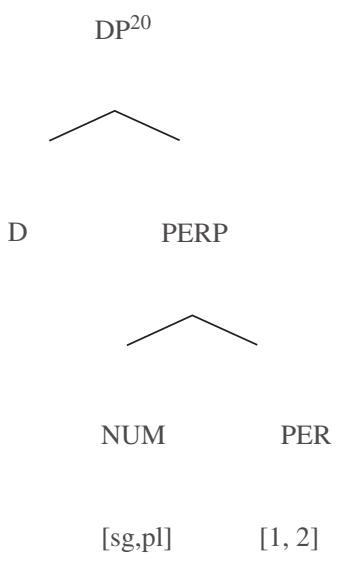

${ }^{21}$ A reviewer points out that it is unclear why 1 st and 2 nd person clitics would need the projection of a $\mathrm{D}$ head, especially if they are object clitics (subject clitics could be taken to relate to the EPP). First of all, as also noted in the main text, for Kratzer the D head would be required for morphophonological reasons, and not for syntactic or semantic reasons. However, the presence of $\mathrm{D}$ in 1 st and 2 nd person object clitics may also be syntactically explained given the analysis proposed in this paper: as I point out later on, direct object clitics check the phi-probe/ obligatory/A EPP and the optional/A-bar EPP feature of $\mathrm{v}^{*}$, while indirect object clitics may check the phi-probe/obligatory/A EPP feature on T (see Anagnostopoulou 2003a). As a result, they are expected to carry a D-feature. In this respect, note that object clitics in Greek do not give rise to Principle $\mathrm{C}$ effects, on a par with subject agreement affixes, as illustrated by the following example:

(i) $\Delta$ en me ${ }_{j}$ ide $e_{i} \quad$ o Kostas $_{i} \quad$ emena $_{j}$. not me.cl saw.3sg. the Kostas.nom me.str.

'Kostas didn't see me.'

In this example, the subject agreement affix binds the subject DP $o$ Kostas without giving rise to Principle $\mathrm{C}$ effects, and the same applies to the object clitic me with regard to the strong object pronoun emena. One could argue that this lends support to the claim that the object clitic me (and therefore, clitics in general) is an agreement affix, or alternatively that it is not a $\mathrm{D}^{0}$-head. Nevertheless, here I assume that the lack of Principle C effects in the case of clitics follows from the fact that they are generated as subparts of their double with which they form a single A-chain. As a result, the clitic behaves as the head of the chain that takes case while the double behaves as the tail of the chain taking only the theta-role and becoming in essence an anaphor. Evidence that case is not assigned to the double is offered by Tsakali (2006). 
As far as indirect object clitics are concerned, I assume that they are also DPs, on a par with direct object clitics. The main reason for this is that on the one hand 3rd person clitics are identical to the definite determiner (besides the genitive plural) and that on the other hand both 3rd as well as 1st and 2nd person clitics obviate locality effects because they check the $\mathrm{D}$ feature off an EPP-T head (see Anagnostopoulou 2003a).

The immediate question that is raised here is about binding theory. That is, if clitics are also DPs, why are they not subject to Principle C, like 3rd person strong pronouns? The simplest answer to this question is that they do not have an NP/root complement, i.e. they do not have a nominal range, which is in essence the difference between a pronoun and an R-expression. As for the $\mathrm{D}^{0}$-head of the clitic, borrowing the 'words' from Borer (2005), it is only an open $\mathrm{D}$ 'range/value' that is contained in the $\mathrm{D}^{0}$-head. Range to this value will be assigned externally via EPP-checking with $\mathrm{v}^{*}$.

\subsection{Proclisis}

In this section I show how the derivation proceeds in proclisis based on the analysis of Greek clitic pronouns given above. Assuming along with Kayne (1975) that clitics move from the object position to their surface position, I argue that the sole role played by the internal structure of clitics with regard to their movement properties are their phi-features which render them valid goals, but nothing else. On the other hand, I argue that the internal structure of clitics does play a role in the incorporation of clitics into their host.

Following Kayne's movement hypothesis, the clitic is merged as a $\mathrm{DP} / \mathrm{D}^{0}$ in the complement position, its phi-features being visible to appropriate probes higher up in the clause. $\mathrm{V}^{0}$ (or possibly some higher verbal $\mathrm{v}$ head), being a phase head by inheritance of phi-features from $\mathrm{v}^{*}$, attracts the clitic to its (external) specifier (A-chain). At the same time, an optional EPP feature at $\mathrm{v}^{*}$, which is linked to a familiarity/-focus/old information $\mathrm{D}$ feature probes and forms a chain with the clitic ( $\mathrm{A}^{\prime}$-chain). The clitic moves as an XP, but lands as an $\mathrm{X}^{0}$ by incorporating into the edge of $\mathrm{v}^{*}$, which is a minimal morphosyntactic phase transparent at the edge. ${ }^{22}$ The incorporated clitic will move along with the $\mathrm{v}^{*}-\mathrm{V}$ complex to $\mathrm{T}^{0}$. The derivation is illustrated below:

\footnotetext{
22 There is also the possibility proposed by Gallego (2006) that in null subject languages $\mathrm{v}^{*}$ reprojects at the $\mathrm{T}$ level, so that in essence we have a complex $\mathrm{v}^{*} / \mathrm{T}$ head. In that case the clitic would move to the edge of the complex $\mathrm{v}^{*} / \mathrm{T}$ head.
} 
(31) $\quad \mathrm{TP}$

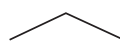

$\mathrm{T}$
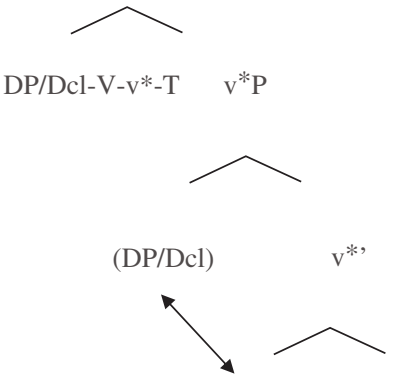

$\left(\mathrm{V}-\mathrm{v}^{*}\right) \quad \mathrm{VP}$

(V) $\quad(\mathrm{DP} / \mathrm{Dcl})$

What happens with full pronouns and other DPs? Why do they not move as well to the periphery of $\mathrm{v}^{*}$ ? One way out would be to speculate that EPP addition is blind to the $\mathrm{DP} / \mathrm{Cl}$ distinction, and that the grammar filters out ungrammatical derivations. In that case, ungrammaticality would follow from independent interface properties as well as from economy considerations. Yet, another way would be to take the clitic to be the realization of the optional/ topic EPP in all environments. Recall that the clitic is in essence a topicalizer. To phrase it differently, the EPP/clitic would be freely added to the numeration, independently of the type of DP complement available. Certain combinations would give rise to cliticization, others to clitic doubling, while others would be infelicitous. In those cases where no EPP is added, we would get the non-doubling instances, which would only involve A-checking by V. So, the following distribution would result:

(32) i) Optional EPP/clitic added //suitable- DP present: clitic doubling

ii) Optional EPP/clitic added// non-suitable DP present: non felicitous clitic doubling

iii) Optional EPP/clitic added//pro DP present: cliticization only

iv) No EPP/clitic added//DP present: no cliticization 
This would work for Greek and other languages that have clitic doubling. In the doubling constructions the clitic would move out of the double DP to the ${ }^{*}$ P periphery, while the doubled DP (i.e. the full DP or pronoun) would stay in situ. This would be possible if we assumed that the clitic is an outer/ external $\mathrm{D}^{0}$ head within the DP encoding familiarity/-focus/old information (see Mavrogiorgos 2009 for more details). In case (iv) the DP or pronoun would not move higher than the periphery of VP, which is the typical object position, as there is no (optional) EPP feature and as a result no clitic.

Going back to incorporation, I assume that it involves morphosyntactic restructuring, which breaks down into two steps: The first step involves 'intrusion' of the clitic into the edge of its host. This takes the form of adjunction, which 'glues' the clitic onto its host (i.e. the clitic becomes morphosyntactically dependent onto it), ensuring that it will be carried along with the host to $T^{0}$. It is some form of super agreement between the clitic and the host that keeps the clitic within the specifier of its host. Another way of looking at intrusion would be as a super feature that keeps on attracting the clitic to the higher specs along the derivation. However, intrusion does not restructure the clitic that is within the spec into a head, as yet. As a result, and due to the fact that the edge remains open until the next higher phase (here I assume the Phase-Impenetrability Condition (PIC) proposed in Chomsky 2001: 14, according to which "the domain of $\mathrm{H}$ is not accessible to operations at $\mathrm{ZP}$; only $\mathrm{H}$ and its edge are accessible to such operations"), the clitic is still visible, as an XP element, to syntax [presumably an EPP feature] (i.e. it is syntactically independent/active), which explains why it retains its XP-properties (projecting an A-spec) when it moves to $\mathrm{T}$, even though morphosyntactically it is part of a complex head (cf. the fact that a genitive clitic in the spec of T may obviate a locality effect (see Anagnostopoulou 2003a)). Morphosyntactic restructuring is completed with the second step, which involves relocation/merger of the feature matrices of the clitic and (the phi-features of) $\mathrm{v}^{*}$. Technically, this is achieved via syntactic agreement and deletion of the phi-feature bundle of $\mathrm{v}^{*}$, and leads to closure of the edge, rendering the clitic (or any other sub-part of the complex head) inaccessible to further (syntactic) operations. As a result, the clitic loses its syntactic independency, becoming a proper sub-part of the host and hence acquiring true head/X properties. This predicts that from this stage on the clitic counts as (part of) a head for syntax, a fact borne out by empirical data that show that the clitic becomes sensitive to the head movement constraint at the $T$ level (see, for example, the blocking effect of negation on clitic climbing, as reported in Kayne 1989).

This analysis predicts that syntactic clitics will always target a phase head (C, $\mathrm{T}, \mathrm{v}^{*}$ or $\mathrm{V}$, depending on parametric variation with regard to feature inheritance 
and the position of object agreement), which naturally captures the essence of special clitics, namely that their cliticization is syntactically motivated. Moreover, it helps us get rid of the extra head movement, which does not bode well with the $\mathrm{XP} / \mathrm{X}^{0}$ status of clitics, and of the extra greedy/look-ahead features which drive this movement: the properties of clitics, then, do not follow from any special features they need to check but from the incorporation operation itself, which saturates them morphosyntactically. Finally, this analysis accounts for the morphological properties of clitics (cf. narrow scope, etc.).

\subsection{The Syntax-Morphology mapping: words as m-phases and clitics}

In this section, I discuss in detail the notion of phase as it is used here. The general idea is taken from Marantz (2001), who proposes that words are (morphosyntactic) phases or spell-out domains, closed-off by functional phase/ categorizing heads, which render them opaque to further operations. Here I propose that certain categories of words are minimal phases (i.e. $\mathrm{PH}^{\mathrm{min}}$ ), namely those that are a lexical phase (i.e. $v, n$, a, etc.) or those that contain a lexical phase. ${ }^{23}$ For instance, a root which has been selected by a phase head $\mathrm{v}$ is a minimal v-phase, and the same applies to other roots with regard to other phase heads. More functional heads may be added, but they will need to have their features valued in order to ensure valid phase-hood. What characterizes a (minimal) phase is that it has a (left) edge (as any other phase). The edge of the phase though (which is defined as the label) is minimally transparent, in the sense that it allows a non-phase to incorporate into it under certain conditions (i.e. sisterhood and proper subset-hood in terms of features) [as opposed to a non-phase, which is fully transparent, and therefore may fully incorporate into an appropriate host]. In this respect, incorporation is viewed as feature restructuring, meaning that the features of the 'incorporee', which are a proper subset of the features of the incorporator, are relocated/ 'sucked' into the label of the host. ${ }^{24}$ Accordingly, the edge becomes the locus of the syntax-morphology interface: it contains lexical information that is relevant to syntax (e.g. phi-features, Tense features, theta-roles and categorial features, which determine the (internal and external) merge position of the word, etc., and hence must be saturated within the syntactic derivation), while on the

\footnotetext{
23 Ian Roberts (p.c.).

24 The idea that featural proper subsethood is a necessary condition for incorporation is taken from Roberts (2009) who argues that: "incorporation can take place only where the label of the incorporee is non-distinct from that of the incorporation host" (Roberts 2009: 75).
} 
other hand it is the place where morphosyntactic restructuring is possible within the syntactic derivation. It follows that the edge will become opaque/ non-accessible (for morphosyntactic operations) as soon as all the features contained in it are checked off. This follows from the fact that spell out domains must be fully interpretable.

The idea that I would like to propose here with regard to phases and clitics is that clitics are not phases and therefore they are able to incorporate into their verbal host, which is a minimal phase, hence minimally transparent at the edge. In this I follow Cardinaletti \& Starke (1999) who suggested that clitics are deficient elements, accounting in this way for a number of their properties. The question of course is why clitics are not phases. Or to put it differently, how do we define non-phases?25 An answer could be that clitics are non-phases because they only contain a $\mathrm{D}^{0}$-head, with no lexical root or any other functional projections to close off. The problem with that is that a $\mathrm{D}^{0}$-head counts as a phase-head and therefore itself as a phase. An alternative analysis would be to assume that although a clitic is a phase head, it has too few features, being a single head. Perhaps, $\mathrm{D}^{0}$ on its own is incomplete, without the lexical $\mathrm{n} / \mathrm{N}$ phase (Ian Roberts, p.c.). As a result, when it moves to the edge of a constituent it can be sucked into it if it is a proper subset of the features of that label. Then, the clitic will become a subpart of the word/phase it incorporates into, and will cease to have access to syntax as soon as the edge is closed off. Incorporation takes place in the way (33) shows:

$$
\mathrm{v}^{*}-\mathrm{V}
$$

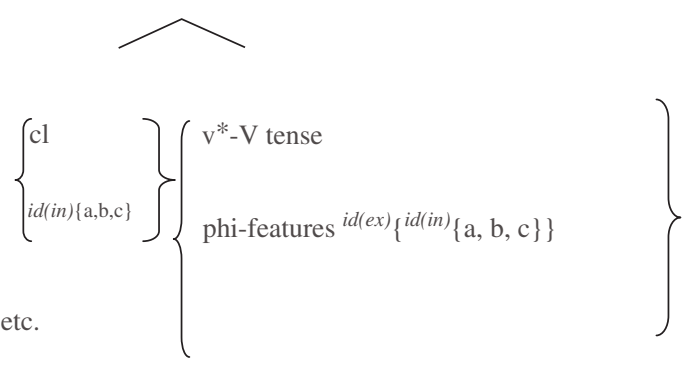

${ }^{25}$ A reviewer wonders whether we really need to justify why clitics are non-phases or how non-phases are defined, and whether it is more crucial to have a justification for what 'qualifies' as a phase, from which it trivially follows what a non-phase is. As pointed out earlier, a minimal phase is defined as the minimal constituent that contains a categorizing/lexical head, such as v, $\mathrm{n}$ or a, following ideas put forward by Marantz (2001). This definition is based on a number of morphological and syntactic facts which show that the categorizing head acts as a phase head in 
In (33) the clitic incorporates into the $\mathrm{v}^{*}-\mathrm{V}$ complex head. It carries phifeatures as well as a D-feature that denotes definiteness (what I call here an internal D index). Unvalued tokens of the same features are found on the complex $\mathrm{v}^{*}-\mathrm{V}$ head with which the clitic agrees. Valuing of the phi-features on $\mathrm{v}^{*}-\mathrm{V}$ and incorporation allow the $i d(e x)$ index (i.e. the external D index, which denotes familiarity, old information, topichood) on the phi-feature bundle of $\mathrm{v}^{*}-\mathrm{V}$ to be copied on the corresponding bundle on the cl. In the second step of morphosyntactic restructuring the $\mathrm{v}^{*}-\mathrm{V}$-phi-bundle is deleted, and the cl-phi-bundle takes up its place (feature matrix substitution/relocation). This is possible only at TRANSFER in the CP phase, since it is only then that the $\mathrm{v}^{*}$-V-bundle (including the $\mathrm{v}^{*}-\mathrm{V}$-phi-bundle) gets deleted. This feature relocation/substitution, which incorporation amounts to, was possible in this case due to the fact that the features of the clitic were a proper subset of the features of the host, namely the $\mathrm{v}^{*}-\mathrm{V}$ head. In other words, the features of the minimal phase $\mathrm{v}^{*}-\mathrm{V}$ were exhausted by the features of the clitic. It is in this respect that I want to call the clitic a non-phase in relation to a phase. It appears then that a non-phase may be a relational notion. As a result, a clitic is a non-phase to a verb but not for example to another clitic (provided these two particular clitics share the same features). ${ }^{26}$

A full DP, on the other hand, may only merge (including pair-merge), being a phase. This is so, because it has more features, and hence it cannot incorporate (i.e. it contains distinct features from another phase/incorporation host). Finally, lexical roots, i.e. bare L-heads, may incorporate into non-phases/ L-roots as well as into little x's (i.e. to phase heads selecting for L-roots), as the latter are the only heads that select for lexical heads/bundles and hence have the appropriate features that trigger incorporation. In other words, on the one hand lexical roots may incorporate with other lexical roots, given that both of them contain only lexical/root features (they are non-phases). On the other hand, categorizing heads may act as hosts to lexical roots, since they contain

the sense of Chomsky (2001a), rendering the root domain inaccessible to further morphological and syntactic operations. As for clitics, it is well known that they do not contain a categorizing head and/or a root (complement) domain to be closed off, and as a result they cannot be taken to contain/be a phase. This is contrary to full DPs, which typically have a categorizer and/or a root domain, and therefore qualify as a phase.

${ }^{26}$ A relevant example would involve constructions with two dative clitics, such as those that have been reported in Spanish (Bleam 1999) and Catalan (Bonet 1991). As for clitic clusters (e.g. direct - indirect object clitics) I assume that the two clitics do not incorporate into each other (given that they contain distinct features); rather, they may only syntactically adjoin with each other, with any further manipulations in their order and internal structure taking place in the post-syntactic morphological component (see Bonet 1991). 
lexical/root features as complement features, i.e. the lexical root exhausts the features on the (selecting) categorizing head. ${ }^{27}$

\subsection{The effect on the outcome: LF and PF saturation of clitics}

Since the clitic host is reinterpreted as an (external) morpho-syntactic phase head, and since phase-heads check off the features of their domains, it follows that the host should check the PF and LF properties/features of the clitic. My claim is that this is the effect of incorporation, which is an additional operation and therefore must have an effect on the outcome.

Clitics cannot be mapped into an independent Prosodic Word (being deficient functional words - cf. Selkirk 1995), therefore they need to be parsed into an adjacent PWd (cf. Principle of Full Interpretation (see Richards 2004)). Incorporation trivially satisfies this requirement, by providing a phonological host to the clitic. In this respect, incorporation has a similar effect to that of shifting in object shift constructions in Germanic languages: in those as well, object shifting provides the weak pronoun with a phonological host (although the movement itself takes place for purely syntactic reasons). In addition, incorporation captures the difference between PF-clitics and syntactic clitics: the latter may only lean onto a specific host (which is a phase head), because they are syntactically attracted to it.

The clitic pronoun in Greek is typically understood as a topicalizer, i.e. a topic marker that marks its double as old or familiar information. I propose that this interpretation is assigned to the doubled DP (overt or pro) via the optional EPP feature the clitic checks on the verbal host when it incorporates. In particular, it gets assigned an external D index, i.e. a familiarity D-head (the outer $\mathrm{D}$ head), that gives it the appropriate interpretation. In this sense,

${ }^{27}$ A reviewer wonders how enclisis works if proclisis involves incorporation at the $\mathrm{v}^{*}$ level: if the clitic has already incorporated inside the $\mathrm{v}^{*} \mathrm{P}$, then imperatives should also show proclisis (irrespectively of V-movement) contrary to fact. For enclisis, I propose that person agreement on $\mathrm{T}$ is defective, while the verb must check verbal inflection on a higher complementizer Modal Head (CM). The clitic targets $\mathrm{v}^{*}$ as in proclisis, however it does not incorporate into it, because $\mathrm{CM}$ is the new phase head by being the highest inflectional verbal head in a chain of verbal heads (phase sliding). The verb moves to CM and the clitic merges with it from the lower specifier of $\mathrm{vP}$ (assuming that $\mathrm{T}$ is not projected in enclitic environments, i.e. in imperatives and gerunds). In this way we get the generalization that enclisis obtains when the verb moves across the cliticization site to a $\mathrm{V}$-related site, i.e. to a site where a verbal inflectional head is found. This allows us to differentiate between imperatives which have $\mathrm{V}$-to- $\mathrm{C}$ movement and take enclitics, from interrogatives, which in some languages have $\mathrm{V}$-to-C movement, but take proclitics. For further details on enclisis see Mavrogiorgos (2009). 
saturation by a (higher) D-category takes place in the syntax giving rise to a special interpretation.

\section{Conclusion}

In this paper, I investigated the internal structure of clitic pronouns and the role the latter possibly plays in cliticization. My main claim was that only their phi-features play a role, by rendering them active goals for the phase head $\mathrm{v}^{*}$ within the $\mathrm{vP}$ phase. I further argued that the internal clitic structure plays a role in the incorporation of the clitic into the verbal host, since only if the clitic is in a subset relation with its host (in terms of features) can it incorporate into it. In order to sustain the above claims, I discussed a number of approaches which have put a great weight upon the internal structure of clitics in relation to clitic movement and showed that they are inadequate to account for the empirical data both in Greek and in other languages. Then, I argued that object clitics are topicalizers, i.e. optional determiner heads merged on top of the proper DP, which mark the direct or indirect object of the clause as topic/old information, and that syntactic cliticization follows from syntactic agreement between the clitic pronoun and a phase head (in this case $\mathrm{v}^{*}$ ). Syntactic agreement between $\mathrm{v}^{*}$ and the clitic leads to movement of the clitic to the left edge of $\mathrm{v}^{*}$ and to incorporation of the clitic into $\mathrm{v}^{*}$. Incorporation yields proclisis and takes place for two interrelated reasons: first, because the clitic contains only a subset of the features contained in $\mathrm{v}^{*}$, and second because the edge of $\mathrm{v}^{*}$ is still open/accessible due to the fact that $\mathrm{v}^{*}$ has not checked all of its features by then. All in all, then, according to this analysis cliticization is simply the result of agree and of an EPP feature on $\mathrm{v}^{*}$, and it is not related to the presence or absence of a particular structure within the clitic head. Incorporation, on the other hand, depends on the featural make-up of the clitic pronoun in relation to the incorporation host.

\section{Acknowledgements}

I would like to thank Ian Roberts, Elena Anagnostopoulou, Adam Ledgeway, and Lila Daskalaki for comments on parts of earlier drafts of this paper. I would also like to thank an anonymous reviewer for his/her helpful comments. Of course the usual disclaimers apply. Finally I would like to thank IKY, the Onassis Foundation and the AHRC for funding the work presented in this paper. 


\section{References}

Abney, Steven P. 1987. The English Noun Phrase in its Sentential Aspect. Ph.D. Dissertation, MIT, Cambridge, Mass.

Alexiadou, Artemis. 2001. Adjective Syntax and Noun Raising: Word Order Asymmetries in the DP as the Result of Adjective Distribution. Studia Linguistica 55: 217-248.

Alexiadou, Artemis. 2004. Inflection Class, Gender and DP Internal Structure. In G. Müller, L. Gunkel, and G. Zifonun (eds.), Exploration in Nominal Inflection, 21-50. Berlin/New York: Mouton de Gruyter.

Alexiadou, Artemis, Haegeman, Liliane and Melita Stavrou. 2007. Noun Phrase in the Generative Perspective. Berlin/New York: Mouton de Gruyter.

Anagnostopoulou, Elena. 1999. Conditions on Clitic Doubling in Greek. In Henk van Riemsdijk (ed.), Clitics in the Languages of Europe, 761-798. Berlin/New York: Mouton de Gruyter.

Anagnostopoulou, Elena. 2003a. The Syntax of Ditransitives. Evidence from Clitics. Berlin/New York: Mouton de Gruyter.

Anagnostopoulou, Elena. 2003b. Review of Phoevos Panagiotidis Pronouns, Clitics and Empty Nouns. Amsterdam/Philadelphia: John Benjamins (2002). Journal of Greek Linguistics 4(1): 157-170.

Anagnostopoulou, Elena. 2006. Clitic Doubling. In Martin Everaert and Henk van Riemsdijk (eds.), The Blackwell Companion of Syntax, 519-581. Oxford: Blackwell.

Anagnostopoulou, Elena and Anastasia Giannakidou. 1995. Clitics and Prominence, or Why Specificity is not Enough. In Papers from the 31st Regional Meeting of the Chicago Linguistics Society, Volume 2: The Parasession on Clitics, 1-14. Chicago: CLS.

Belletti, Adriana. 1999. Italian/Romance Clitics: Structure and Derivation. In Henk van Riemsdijk (ed.), Clitics in the Languages of Europe, 543-582. Berlin/New York: Mouton de Gruyter.

Benveniste, Emile. 1971. Problems in general linguistics. Coral Gables, FL: University of Miami Press.

Bibis, Nick. 2002. The Syntax of Clitics in Idiomatic and Other Fixed Expressions. Ph.D. Dissertation, University of Toronto.

Bleam, Tonia. 1999. Leista Spanish and the Syntax of Clitic Doubling. Ph.D. Dissertation, University of Delaware.

Bonet, María Luisa. 1991. The Lengths of Propositional Proofs and the Deduction Rule. Ph.D. Dissertation, University of California, Berkeley.

Borer, Hagit. 2005. Structuring Sense: Vol. I: In Name Only. Oxford: OUP.

Cardinaletti, Anna. 1994. On the Internal Structure of Pronominal DPs. The Linguistic Review 11: $195-219$.

Cardinaletti, Anna and Michel Starke. 1999. The Typology of Structural Deficiency: A Case Study of the Three Classes of Pronouns. In Henk van Riemsdijk (ed.), Clitics in the Languages of Europe, 145-233. Berlin: Mouton de Gruyter.

Chomsky, Noam. 1981. Lectures on Government and Binding. Dordrecht: Foris.

Chomsky, Noam. 1993. A Minimalist Program for Linguistic Theory. In Ken Hale and Samuel J. Keyser (eds.), The View from Building 20: Essays in Linguistics in Honor of Sylvain Bromberger, 1-52. Cambridge, MA: The MIT Press.

Chomsky, Noam. 1995. The Minimalist Program. Cambridge, MA: The MIT Press.

Chomsky, Noam. 2000. Minimalist Inquiries: The Framework. In Roger Martin, David Michaels, and Juan Uriagereka (eds.), Step by Step: Essays on Minimalist Syntax in Honor of Howard Lasnik, 89-155. Cambridge, MA: The MIT Press. 
Chomsky, Noam. 2001. Derivation by Phase. In Michael Kenstowicz (ed.), Ken Hale: A Life in Language, 1-52. Cambridge, Mass.: MIT Press.

Chomsky, Noam. 2005. On Phases. Ms., MIT. (Now published in Robert Freidin, Carlos Otero and Maria-Luisa Zubizarreta (eds.) 2008, Foundational Issues in Linguistic Theory. Essays in Honor of Jean-Roger Vergnaud. 133-66. Cambridge, MA: MIT Press.)

Chomsky, Noam. 2007. Approaching UG from Below. In Uli Sauerland and Hans-Martin Gärtner, (eds.), Interfaces + Recursion $=$ Language? 1-29. Berlin: Mouton de Gruyter.

Condoravdi, Cleo and Paul Kiparsky. 2001. Clitics and Clause Structure. Journal of Greek Linguistics 2: 1-39.

Condoravdi, Cleo and Paul Kiparsky. 2004. Clitics and Clause Structure: The Late Medieval Greek System. Journal of Greek Linguistics 5: 159-183.

Corbett, Greville G. 1991. Gender. Cambridge: CUP.

Corbett, Greville G. 2006. Agreement. Cambridge: CUP.

Corver, Norbert and Dennis Delfitto. 1993/1999. On the Nature of Pronoun Movement. In Henk van Riemsdijk (ed.), Clitics in the Languages of Europe, 799-864. Berlin/New York: Mouton de Gruyter.

de Hoop, Helen. 1992. Case Configuration and Noun Phrase Interpretation. Ph.D. Dissertation, University of Groningen.

de Hoop, Helen. 1996. Case Configuration and Noun Phrase Interpretation. Garland: New York.

de Hoop, Helen. 2000. Optional Scrambling and Interpretation. In Hans Bennis, Martin Everaert and Eric Reuland (eds.), Interface Strategies: Proceedings of the colloquium, Amsterdam, 24-26 September 1997, 153-168. Amsterdam: Koninklijke Nederlandse Akademie van Wetenschappen.

Déchaine, Rose-Marie and Martina Wiltschko. 2002. Decomposing Pronouns. Linguistic Inquiry 33(3): 409-442.

Diesing, Molly. 1992. Indefinites. Cambridge, MA: The MIT Press.

Diesing, Molly. 1996. NP Types and Conditions on Interpretation. In Jan Don, Bert Schouten and Wim Zonneveld (eds.), OTS Yearbook 1995, 1-12. Utrecht: Onderzoeksinstituut voor Taal en Spraak, Utrecht University.

Diesing, Molly. 1997. Yiddish VP Order and the Typology of Object Movement in Germanic. Natural Language and Linguistic Theory 15: 369-427.

Diesing, Molly and Eloise Jelinek 1995. Distributing Arguments. Natural Language Semantics 3: 123-176.

Drachman, Gaberell. 1997. Some Properties of Clitics (With Special Reference to Modern Greek). In Artemis Alexiadou and T. Alan Hall, (eds.), Studies on Universal Grammar and Typological Variation, 219-248. Amsterdam: John Benjamins.

Elbourne, Paul. 2005. Situations and Individuals. Cambridge, Mass.: MIT Press.

Gallego, Ángel. 2006. Phase Sliding. Unpublished ms., UAB and UMD.

Giannakidou, Anastasia and Melita Stavrou. 1999. Nominalization and Ellipsis in the Greek DP. Linguistic Review 16: 295- 331.

Giusti, Giuliana. 1997. The Categorial Status of Determiners. In Liliane Haegeman (ed.), The New Comparative Syntax, 95-124. London: Longman.

Grimshaw, Jane. 1991. Extended Projection. Unpublished ms., Brandeis University.

Grodzinsky, Yosef and Tanya Reinhart (1993) The Innateness of Binding and Coreference. Linguistic Inquiry 24(1): 69-101.

Heim, Irene and Angelika Kratzer. 1998. Semantics in Generative Grammar. Oxford: Blackwell. Higginbotham, James. 1985. On Semantics. Linguistic Inquiry 16(4): 547-594.

Holmberg, Anders. 2005. Is There a Little Pro? Evidence from Finnish. Linguistic Inquiry 36(4): 533-564. 
Jaeggli, Osvaldo. 1986. Three Issues In the Theory of Clitics: Case, Doubled NPs, and Extraction. In Hagit Borer (ed.), Syntax and Semantics 19: The Syntax of Pronominal Clitics, 15-42. Orlando: Academic Press.

Joseph, Brian D. 1988. Pronominal Affixes in Modern Greek: The Case Against Clisis. In D. Brentari et al. (eds.), Papers from the 24th Regional Meeting, Chicago Linguistic Society (1988), 203-215.

Joseph, Brian. 2001. On an Oddity in the Development of Weak Pronouns in Deictic Expressions in the Languages of the Balkans. In D. Dyer \& V. Friedman (eds.), Of All the Slavs my Favorites. In Honor of Howard I. Aronson on the Occasion of his 66th Birthday (Special issue of Indiana Slavic Studies, vol. 12, 2001), 251-267.

Julien, Marit. 2002. Syntactic Heads and Word Formation. Oxford: OUP.

Kayne, Richard S. 1975. French Syntax. The Transformational Cycle. Cambridge, MA: The MIT Press.

Kayne, Richard S. 1989. Null Subjects and Clitic Climbing. In Osvaldo Jaeggli and Kenneth J. Safir (eds.), The Null Subject Parameter, 239-261. Dordrecht: Kluwer.

Kratzer, Angelika. 2009. Making A Pronoun: Fake Indexicals as Windows into the Properties of Pronouns. Linguistic Inquiry 40(2): 187-237.

Laenzlinger, C. 1998. Comparative Studies in Word Order Variations: Pronouns, Adverbs and German Clause Structure. Amsterdam/Philadelphia: John Benjamins.

Lobeck, Anne C. 1991. Phrase structure of ellipsis in English. In Susan D. Rothstein (ed.), Perspectives on phrase structure: Heads and licensing, 81-107. Syntax and Semantics 25. San Diego, CA: Academic Press.

Lobeck, Anne C. 1995. Ellipsis, Functional Heads, Licensing and Identification. Oxford: OUP.

Manzini, M. Rita and Leonard M. Savoia. 2005. I dialetti italiani e romanci. Morfosintassi generativa. Alessandria: Edizioni dell'Orso, 3vols.

Manzini, M. Rita and Leonard M. Savoia. 2007. A unification of morphology and syntax. Studies in Romance and Albanian dialects. London: Routledge.

Marantz, Alec. 2001. 'Words'. Handout from West Coast Conference on Formal Linguistics XX, Feb. 23-25, USC.

Marantz, Alec. 2006. Phases and words. Unpublished ms, NYU.

Matushansky, Ora. 2006. Head Movement in Linguistic Theory. Linguistic Inquiry 37: 69-109.

Mavrogiorgos, Marios. 2009. Proclisis and Enclisis in Greek. Ph.D. Dissertation, University of Cambridge.

Merchant, Jason. 1999. The Syntax of Silence: Sluicing, Islands and Identity in Ellipsis. Ph.D. Dissertation, University of California, Santa Cruz.

Panagiotidis, Phoevos. 2002. Pronouns, Clitics and Empty Nouns. Amsterdam/Philadelphia: John Benjamins.

Pappas, Panayiotis. 2004. Medieval Greek Weak Object Pronouns and Analogical Change. A Response to Condoravdi \& Kiparsky (2001). Journal of Greek Linguistics 5: 127-157.

Postal, Paul M. 1969. On so-called 'pronouns' in English. In David Reibel and Sanford Schane (eds.), Modern Studies in English, 201-224. Englewood Cliffs, NJ: Prentice- Hall.

Ralli, Angela. 2000. A feature-based analysis of Greek nominal inflection. Glossologia 11-12: 201-227.

Ralli, Angela. 2002. The Role of Morphology in Gender Determination: Evidence from Modern Greek. Linguistics 40(3): 519-551.

Ralli, Angela. 2003. O Kathorismos tou Grammatikou Genous sta Ousiastika tis Neas Elinikis. [Gender Determination on Nouns in Modern Greek.] In Anna AnastasiadiSymeonidi, Angela Ralli and Despina Hila-Markopoulou (eds.), To Genos, 57-99. Athens: Patakis. 
Richards, Marc. 2004. Object Shift and Scrambling in North and West Germanic: A Case Study in Symmetrical Syntax. Ph.D. Dissertation, University of Cambridge.

Ritter, Elizabeth. 1993. Where's Gender? Linguistic Inquiry 24: 795-803.

Rizzi, Luigi. 1993. Some Notes on Romance Cliticization. Presentation at the Eurotyp Group on Clitics, October 1993, Durham.

Roberts, Ian. 1993. Verbs and Diachronic Syntax. Dordrecht: Kluwer.

Roberts, Ian. 2009. Agreement and Head movement: Clitics, Incorporation and Defective Goals. Unpublished ms., University of Cambridge.

Roca, Francesc. 1992. Object Clitics in Spanish and Catalan. Catalan Working Papers in Linguistics 2: 245-280.

Rohrbacher, Bernhard W. 1994. The Germanic VO Languages and the Full Paradigm: A Theory of $V$ to I Raising. Ph.D. Dissertation, University of Massachusetts Amherst.

Sportiche, Dominique. 1990. Movement, Case and Agreement. Unpublished ms., UCLA.

Sportiche, Dominique. 1992/1998. Clitic Constructions. In Dominique Sportiche, Partitions and Atoms of Clause Structure: Subjects, Agreement, Case and Clitics. London/ New York: Routledge.

Suñer, Margarita (1988) The Role of Agreement in Clitic-Doubled Constructions. Natural Language and Linguistic Theory 6: 391-434.

Ticio, M. Emma. 2003. On the Structure of DPs. Ph.D. Dissertation, University of Connecticut.

Ticio, M. Emma. 2005. Locality and Anti-locality in Spanish DPs. Syntax 8 (3): 229-286.

Torrego, Esther. 1988. Pronouns and determiners: A DP analysis of Spanish nominals. Unpublished ms., University of Massachusetts, Boston.

Tsakali, Vina. 2006. The Syntax and Acquisition of Pronominal Clitics: a Crosslinguistic Study with Special Reference to Modern Greek. Ph.D. Dissertation, UCL.

Uriagereka, Juan. 1995. Aspects of the Syntax of Clitic Placement in Western Romance. Linguistic Inquiry 26: 79-124.

van der, Does, Jaap and Helen de Hoop. 1998. Type-shifting and Scrambled Definites. Journal of Semantics 15(4): 393-416.

Vikner, Sven 1995. Verb Movement and Expletive Subjects in the Germanic Languages. Oxford: OUP. 